\title{
Regulatory T cells in many flavors control asthma
}

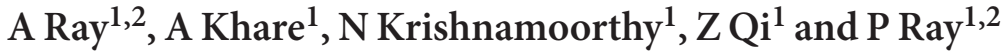

That regulatory $T$ cells (Tregs) have a crucial role in controlling allergic diseases such as asthma is now undisputed. The cytokines most commonly implicated in Treg-mediated suppression of allergic asthma are transforming growth factor- $\beta$ (TGF- $\beta$ ) and interleukin (IL)-10). In addition to naturally occurring Tregs, adaptive Tregs, induced in response to foreign antigens, have been shown in recent studies. The concept of inducible/adaptive Tregs (iTregs) has considerable significance in preventing asthma if generated early enough in life. This is because cytokines such as IL-4 and IL-6 inhibit Foxp3 induction in naive CD4 + T cells and therefore de novo generation of Tregs can be expected to be less efficient when it is concomitant with effector cell development in response to an allergen. However, if iTregs can be induced, the process of infectious tolerance would facilitate expansion of the iTreg pool as suggested in the recent literature. It is tempting to speculate that there is a window of opportunity in early life in the context of a relatively immature immune system that is permissive for the generation of iTregs specific to a spectrum of allergens that would regulate asthma for lifelong. The focus of this review is the relevance of $n$ Tregs and iTregs in controlling asthma from early life into adulthood, the mechanisms underlying Treg function, and the prospects for using our current concepts to harness the full potential of Tregs to limit disease development and progression.

\section{INTRODUCTION}

Various lines of evidence indicate that $\mathrm{T}$ helper cells (CD4+ $\mathrm{T}$ cells) and their secreted products have a central role in orchestrating the unique inflammatory response in the airways of asthmatics. Local allergen challenge has been shown to induce an influx of CD4 $+\mathrm{T}$ cells and eosinophils into the airways of asthmatics. ${ }^{1}$ In a mouse model, depletion of $\mathrm{CD} 4+\mathrm{T}$ cells with a monoclonal antibody to CD4 antigen reduced airway eosinophilia and eliminated airway hyperresponsiveness. ${ }^{2}$ Thelper 2 type (Th2) cells are believed to augment the inflammatory response observed in asthma by expressing multiple cytokines such as interleukin (IL)-4, IL-5, IL-9, and IL-13, each of which could potentially augment the eosinophilic inflammation in asthma. ${ }^{3-7}$ In addition to eosinophils, other cell types are also involved in asthma pathogenesis as reviewed recently. ${ }^{8}$ For example, neutrophilic asthma is also well recognized and is associated with severe airflow obstruction, which is difficult to control by corticosteroids. ${ }^{9}$ A more recently identified T helper subset, Th17, has been implicated in neutrophil-dominated asthma ${ }^{10-12}$ and was shown to be responsible for steroid resistance in a murine model of asthma. ${ }^{13}$ The effector function of all T helper cells, Th1, Th2, and Th17, is regulated by regulatory $\mathrm{T}$ cells (Tregs). This ensures protection from autoimmune diseases such as diabetes and multiple sclerosis as well as allergic diseases such as eczema and asthma. In this study we discuss recent findings that suggest an important role for Tregs in the induction of tolerance to environmental allergens and in limiting disease when allergic airway inflammation is induced. Also discussed are current concepts about development of Tregs and Treg-expressed mediators that have relevance in controlling asthma and how this knowledge might be exploited to enhance Treg function. Table 1 enlists Treg-associated nomenclature commonly used in the literature to describe different types of Tregs and their regulatory role in controlling inflammation in the lung or the gut.

FROM BIRTHTO ADULTHOODTREGS MAKE A DIFFERENCE The phenomenon of tolerance was introduced by Owen in 1945 in his seminal observations of "mosaicism" (red cell chimerism) in adult cattle dizygotic twins. ${ }^{14} \mathrm{~A}$ few years later in 1953, acquisition of tolerance to foreign allograft antigens in utero was shown in mice by Billingham et al. ${ }^{15}$ Some 50 years later, the concept of acquired tolerance to foreign antigens is highly significant not only in the context of transplantation tolerance but also in the realm of allergic and autoimmune diseases. Enmeshed in the concept of acquired immune tolerance is the fabric of the "hygiene hypothesis," which was postulated to explain the increased prevalence of allergic diseases in developed

\footnotetext{
${ }^{1}$ Division of Pulmonary, Allergy and Critical Care Medicine, Department of Medicine, University of Pittsburgh School of Medicine, Pittsburgh, Pennsylvania, USA.

2Department of Immunology, University of Pittsburgh School of Medicine, Pittsburgh, Pennsylvania, USA. Correspondence: A Ray (raya@pitt.edu)

Received 15 December 2009; accepted 21 January 2010; published online 17 February 2010. doi:10.1038/mi.2010.4
} 
Table 1 Treg nomenclature and relevance in immune regulation in the lung and the gut

\begin{tabular}{|c|c|c|c|}
\hline \multirow{2}{*}{$\begin{array}{l}\text { Types of } \\
\text { Tregs }\end{array}$} & \multirow{2}{*}{$\begin{array}{l}\text { Phenotype and } \\
\text { original identifi- } \\
\text { cation }\end{array}$} & \multicolumn{2}{|c|}{ Mucosal relevance } \\
\hline & & Lung & Gut \\
\hline \multirow[t]{2}{*}{$\begin{array}{l}\text { Thymically } \\
\text { derived } \\
\text { nTregs }\end{array}$} & $\begin{array}{l}\text { CD4 + CD25 } \\
\text { Foxp3 }+ \\
(\text { mice })^{221}\end{array}$ & Ref. $44,54,55,73,90$ & \\
\hline & $\begin{array}{l}\text { CD4 + CD25 hi } \\
\text { Foxp3 + CD49d- } \\
\text { (human) }^{222}\end{array}$ & Ref. 33,35,36,202 & Ref. 76 \\
\hline $\begin{array}{l}\text { Peripherally } \\
\text { induced } \\
\text { adaptive } \\
\text { Tregs (iTregs) }\end{array}$ & $\begin{array}{l}\text { Peripherally } \\
\text { induced from } \\
\text { CD4 + CD } 25- \\
\text { cells. The regula- } \\
\text { tory T cells could } \\
\text { be Foxp3 + or } \\
\text { Foxp3- }\end{array}$ & & \\
\hline $\begin{array}{l}\text { (i) Foxp3 + } \\
\text { iTreg }\end{array}$ & $\begin{array}{l}\text { CD4 + CD25 } \\
\text { Foxp3 + (mice })^{53}\end{array}$ & $\begin{array}{l}\text { Ref. } 48,53,51 \\
61,144\end{array}$ & \\
\hline $\begin{array}{l}\text { (ii) Foxp3 - } \\
\text { Tr1 cells }\end{array}$ & $\begin{array}{l}\text { IL-10-expressing } \\
\text { CD4 + CD25 } \\
\text { Foxp3-34 }\end{array}$ & $\begin{array}{l}\text { Ref. } 42,43,45, \\
46,49,118,158,159\end{array}$ & $\begin{array}{l}\text { Ref. } 24,25 \\
34,40\end{array}$ \\
\hline $\begin{array}{l}\text { (iii) Foxp3- } \\
\text { Th3 cells }\end{array}$ & $\begin{array}{l}\text { TGF- } \beta \text {-expressing } \\
\text { CD4 + T cells }\end{array}$ & \multicolumn{2}{|c|}{$\begin{array}{l}\text { Have yet to be associated } \\
\text { with immune suppression in } \\
\text { the lung or the gut }\end{array}$} \\
\hline ExFoxp3 & $\begin{array}{l}\text { CD4 + CD25hi } \\
\text { Foxp3 + Treg } \\
\text { cells that have } \\
\text { spontaneously } \\
\text { lost Foxp3 } \\
\text { expression and } \\
\text { secrete pro- } \\
\text { inflammatory } \\
\text { cytokines } \\
\text { 93,94 }\end{array}$ & & Ref. 94 \\
\hline
\end{tabular}

IL-10, interleukin-10; TGF- $\beta$, transforming growth factor- $\beta$.

countries in recent years. The basic tenet of this hypothesis is that early childhood exposures to pathogen-associated products inversely correlates with the incidence of allergic diseases in adulthood. Initially postulated in $1989,{ }^{16}$ the underlying mechanism associated with this hypothesis was Th1/Th2 crossregulation. However, after epidemiological studies showed that Th2-inducing parasitic infections could protect from atopic diseases that are also engendered by Th 2 cells, it became clear that additional mechanisms are needed to be invoked to explain the protective effect of microbial exposures. ${ }^{17,18}$ The need for a more general immunoregulatory mechanism was realized when the same beneficial effect of microbes on Th1-induced diseases such as autoimmune diseases was also evident. With the rapid progress of research in the field of Tregs in recent years, it seems that microbial infections are conducive to the development of these cells, ${ }^{19,20}$ which are then able to exercise their immunosuppressive functions to dampen unwarranted immune responses against foreign or self-antigens.

There is significant interest in understanding the development of the immune system from the fetus to adulthood to help define the triggers and brakes in the etiology of allergic diseases. It is now well recognized that microbes can induce the production of the suppressive cytokines transforming growth factor- $\beta$ (TGF- $\beta$ ) and IL- $10 .{ }^{17,19,21-23}$ It is noteworthy that IL-10 knockout mice develop colitis and a recent study has shown that it is the secretion of this cytokine from myeloid-derived cells stimulated by microbiota that prevents the induction of colitis. ${ }^{24,25}$ Similarly, mice bearing a dominant-negative mutation in the TGF- $\beta$ receptor on CD4 $\mathrm{T}$ cells show profound inflammation in various organs, including the lungs, liver, and the pancreatic islets, suggesting impaired development of Tregs. ${ }^{26}$

Recent studies in humans and mice show the importance of Tregs in the promotion of tolerance to foreign antigens transmitted through the placenta to the fetus. ${ }^{27}$ The mother during pregnancy is exposed to several antigens from the environment and these antigens, termed "non-inherited maternal antigens," constantly traverse the placenta and have the capacity to evoke an immune response. How is the mounting of immune response to these foreign antigens stumped in the developing fetus? A study in humans showed that maternal cells traffic in large numbers to fetal lymph nodes to induce CD4 + CD25 + Foxp3 + cells with suppressive functions that prevent antimaternal immunity lasting until early adulthood. This study also challenges the preconceived notion that fetal lymphocytes are incapable of mounting an immune response ${ }^{28}$ (Figure 1). In fact, the data from this study show that fetal lymphocytes secrete high levels of cytokines in response to non-inherited maternal antigens when Tregs have been selectively depleted. In a study in mice in which the protocol of aerosolized ovalbumin (OVA) was used to induce airway tolerance in mothers, transfer of OVA and TGF- $\beta$ through breast milk into suckling neonates induced suppressive $\mathrm{CD} 4+\mathrm{T}$ cells whose generation depended on a functional TGF- $\beta$ receptor ${ }^{29}$ (Figure 1). Similarly, when pregnant female mice were tolerized to antigen, the offspring were also tolerized to the same antigen, which was sustained only when the infants were nursed by the tolerized mothers. ${ }^{30}$ These studies suggest that foreign antigens can be transferred across the placenta or through breast milk to fetuses or infants, respectively, who can induce Foxp3-expressing Tregs in the presence of TGF- $\beta$. The findings not only underscore the importance of Tregs in tempering immune responses in the developing fetus but also highlight a window of opportunity for the development of novel therapeutics in early life to ward off disease. ${ }^{31,32}$ Thus, it may not be too fanciful to propose administration of minute doses of a cocktail of allergens to expectant mothers or neonates to develop antigen-specific Tregs that would provide life-long protection from developing allergic diseases such as asthma (Figure 1).

\section{WHICH MECHANISM IS RELEVANT-FOXP3 + TREGS OR IL-10-IN EXPRESSING TR1-LIKE CELLS?}

It is clear that individuals with defective or suboptimal Foxp3 expression due to mutations in the Foxp 3 gene (immunodysregulation polyendocrinopathy enteropathy X-linked (IPEX) syndrome) or in genes that promote Foxp3 expression, such as STAT5b, are susceptible to allergic disease. ${ }^{33}$ This section will review studies in both humans and rodents that suggest the importance of both Foxp3-expressing Tregs and IL-10the source of the latter not necessarily being Foxp3-expressing 


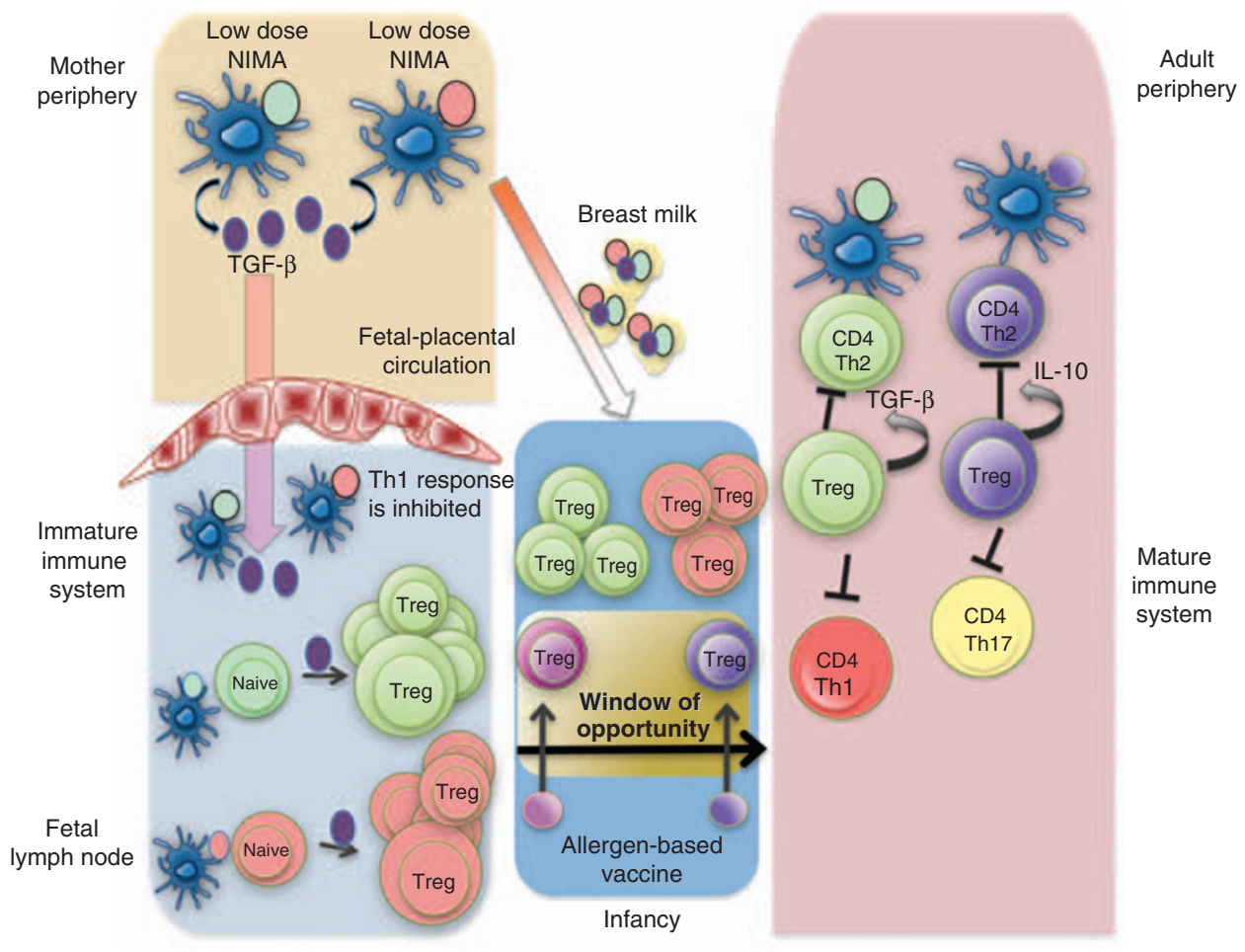

Figure 1 Induced Tregs specific to allergens in early life may be the elixir of asthma-free life. As shown recently, ${ }^{28}$ the fetus is constantly exposed to non-inherited maternal antigens (NIMA) that traverse the placenta and trigger the development of Tregs in the fetal lymph nodes. Tregs constitute a high percentage of total lymphocytes in the fetal lymph nodes. This pool of Tregs aids in tempering fetal immune responses against maternal antigens. During or after pregnancy, transfer of antigen and transforming growth factor- $\beta$ (TGF- $\beta$ ) across the placenta or through breast milk induces antigenspecific Tregs. ${ }^{29,30}$ The immune system's ability to induce antigen-specific Tregs in early life suggests a unique window of opportunity to administer allergen-based vaccines to infants for the induction of protective allergen-specific Tregs.

cells-in regulating allergic asthma. CD4 + T cells that do not express Foxp3 but secrete IL-10 and suppress effector functions of T helper cells are known as Tr1 cells. ${ }^{34}$

In humans, along with typical disease manifestations such as elevated immunoglobulin E (IgE) levels, eczema, and insulindependent diabetes mellitus, intestinal inflammation, asthma, and other recurrent respiratory disorders have also been associated with IPEX. ${ }^{35-37}$ Although eczema is a common feature of IPEX deficiency, there is less documentation of asthma in IPEX patients. The most likely reason for this is that there is inherently significant uncertainty in the diagnosis of asthma in young children. Although wheezing is a phenotype of asthma, it is not a definitive diagnosis of this disease in young children. A vast majority of infants and children of $<6$ years of age show wheezing during recurrent respiratory infections, but the children outgrow the phenotype with age. ${ }^{38}$ Because of the difficulty in diagnosing asthma in early life, asthma is not as commonly associated with IPEX as is eczema, which manifests in infants and is easily diagnosed. For example, in one study of 14 patients, all of whom were diagnosed early with severe disease symptoms including eczema, only one was diagnosed with asthma. This patient underwent spontaneous remission of early diarrhea and all traces of autoimmunity at age 4 , but was left with mild eczema, relatively high serum IgE levels, and occasional upper respiratory tract infections. ${ }^{39}$ Whether asthma also persisted is not documented in the report. This patient had two mutations in Foxp3-one a silent mutation at the intron 4/exon
5 boundary that presumably influences RNA splicing and another non-conservative mutation in the FKH domain. It is possible that these mutations allowed some level of expression of functional Foxp 3 in later life that was adequate to suppress autoimmunity but not allergic disease. In another study, CD25 deficiency was associated with reduced IL-10 expression and the patient developed symptoms indistinguishable from those observed in IPEX patients with the patient progressing to develop asthma. ${ }^{40}$ As it is now well recognized that IL-2 is required to maintain Foxp3+ Tregs in the periphery, ${ }^{41}$ it is not surprising that this patient showed an IPEXlike phenotype. Most importantly, the development of asthma in this suggests an important regulatory role for Foxp $3+$ Tregs in asthma. In another study, maintenance of tolerance to beestings in beekeepers by seasonal exposure to bee stings was found to be associated with increased bee venom antigen-specific IL-10-producing CD4 + Tr1-like cells. ${ }^{42,43}$ Hence, what are the sources of IL-10 and TGF- $\beta$ and their contribution in suppression of allergic asthma when expressed from a Foxp3-expressing cell or a Foxp3-negative cell? Interestingly, two types of nTregs that develop in the thymus have been recently described-ICOS ${ }^{-}$and $\mathrm{ICOS}^{+}$- that use TGF- $\beta$ and IL-10, respectively, for their suppressive functions. ${ }^{44}$

A review of animal studies on the role of Tregs in regulating allergic asthma reveals an interesting difference in the involvement of IL-10 vs. Foxp3-expressing Tregs, depending on whether or not the animals were sensitized through the airways. In multiple studies that used the intraperitoneal mode of antigen 
sensitization, in which non-airway dendritic cells (DCs; such as splenic DCs) would be involved in priming naive T helper cells, a dependence on IL-10 for suppression of effector T-cell responses and airway pathology was noted. An exception to this general trend is the results of one study that used intranasal delivery of adjuvant-free OVA, in which an involvement of IL-10 in suppressing allergic airway inflammation was noted ${ }^{45}$ that involved the ICOS-ICOS ligand pathway. ${ }^{46}$ There does not seem to be an agreement in the different studies with respect to the source of IL-10. In one study, the source was found to be not the Foxp3-expressing cells but actually bystander CD4 + T cells. ${ }^{47}$ In contrast, a different study showed that deletion of IL10 in Foxp3-expressing CD4 + T cells promoted allergic airways disease. ${ }^{48}$ In a recent study, in which peptides derived from the cat allergen, Fel d 1, were delivered intradermally to promote immunotherapy in mice previously immunized by the intraperitoneal route, IL-10-producing cells but not TGF- $\beta$-expressing Foxp $3+$ Tregs were found to mediate immune suppression. ${ }^{49}$ In our own studies of tolerance induction through repeated exposure to a low dose of aerosolized antigen, a protocol initially established by Holt and colleagues, ${ }^{50}$ an involvement of Foxp3 + Tregs expressing membrane-bound TGF- $\beta$ in mediating resistance to development of antigen-induced airway inflammation was identified. ${ }^{51,52}$ In another study of oral tolerance, Foxp3 + Tregs were shown to inhibit allergic airway inflammation that was dependent on TGF- $\beta$ and not IL- $10 .{ }^{53}$ Similarly, when animals were immunized by intratracheal delivery of the allergen house dust mite, depletion of $\mathrm{CD} 25^{\text {hi }}$ population of cells induced airway hyperresponsiveness in a normally resistant mouse strain C $3 \mathrm{H} .{ }^{54}$ In this study, no involvement of IL-10 was apparent. ${ }^{54}$ Thus, it is clear that no single mechanism of Treg-mediated suppression of allergic airways disease has emerged from multiple studies of experimental asthma reported to date.

As a dependence on IL-10 for suppression was not evident in models in which the antigen was delivered through the respiratory route, ${ }^{52-54}$ which was the opposite when a non-airway mode was adopted, ${ }^{43,47-49,55}$ it seems that the cell types that are engaged as suppressive cells in the two settings of antigen exposure are distinct. When animals were repeatedly exposed to inhaled antigen without any adjuvant such that sufficient maturation of airway DCs would not occur, Foxp3 + Tregs expressing membrane-bound TGF- $\beta$ were found to mediate inhibition of allergic inflammation in the airways. ${ }^{52}$ Conversely, conversion of a normally resistant mouse strain susceptible to development of an asthma phenotype by depletion of $\mathrm{CD} 25^{\text {hi }}$ cells was a direct effect of loss of attenuation of lung DC costimulatory functions by Tregs promoting unopposed inflammatory effects of $\mathrm{T}$ helper cells. ${ }^{54}$ On the other hand, if effector cells and their regulators were primarily induced at a distant site, such as the $\operatorname{skin}^{49}$ or the spleen, ${ }^{55,47}$ IL-10 seemed to be an important negative regulator of pulmonary disease development, as was also suggested in the study of bee keepers. ${ }^{42,43}$ The primary reason for this difference maybe that when Tregs are activated locally in the lung-draining lymph nodes, particularly in the presence of a low dose of antigen, IL-10 gene expression is not favored either from the Tregs or from bystander cells in the tissue. However, if IL-10 gene expression is induced when priming occurs elsewhere, the source of the cytokine maybe the Foxp3-expressing cell ${ }^{48}$ or a bystander cell. ${ }^{47}$ It seems likely that IL-10 production is determined by the dose and T-cell receptor (TCR) affinity of the antigen, the adjuvant used, or other properties for a complex allergen, such as ligands, for pattern recognition receptors. A topic for future exploration is differential distribution of Foxp3 + Tregs that use TGF- $\beta$ vs. IL- 10 in the periphery.

Another possible explanation for the involvement of Foxp3+ Tregs expressing membrane-bound TGF- $\beta$ rather than IL-10 in mediating tolerance in the airways is the relative enrichment of Foxp3 + Tregs in mucosal tissues and in lymph nodes draining the lung and the gut. Although a proportion of these Tregs may be induced de novo, polyclonally expanded locally residing $\mathrm{ICOS}^{-}$nTregs may also be involved in disease suppression (discussed in the following section). However, when Tregs are induced after immunization with antigen and adjuvant delivered through the skin or spleen, IL-10 and not TGF- $\beta$ produced by Foxp3 + Tregs (probably $\left.\mathrm{ICOS}^{-}\right)^{44}$ or Foxp3 - Tr1-like cells (probably $\left.\mathrm{ICOS}^{+}\right)^{44}$ limit the severity of inflammation. It is clear, however, that Foxp3 deficiency promotes allergic disease. ${ }^{35,36}$ Therefore, regardless of whether or not IL-10 or TGF- $\beta$ is the mediator of suppression of asthma or other allergic diseases such as eczema, Foxp3-expressing Tregs are important negative regulators of allergic disease. It will be useful to determine in future studies what conditions induce IL-10 production from a Foxp3-expressing cell even when it is not innately programmed to express IL-10. ${ }^{44}$ If such conditions could be established in situations in which Foxp3 is mutated or its expression is suboptimal, as observed in IPEX patients, IL-10 could potentially substitute for Foxp3-dependent suppressive mechanisms. As eczema/atopic dermatitis develops early in life in most IPEX patients, such strategies may need to be directed to the skin, which may also protect the lung (peptide immunotherapy).

\section{ROLE OFTHYMUS-DERIVEDTREGS (NTREGS) VS. PERIPHERALLY INDUCEDTREGS (ITREGS) IN REGULATING ALLERGIC ASTHMA}

The generation of Foxp 3 + Tregs in vitro by activation of CD $4+$ T cells in the presence of TGF- $\beta$ showed that acquisition of Foxp3 is possible in a non-thymic environment. ${ }^{56}$ Although the identification of CD4 + CD25 + Foxp3 + T cells after adoptive transfer of naive CD4 + T cells into recipient TCR transgenic mice devoid of nTregs also suggested similar de novo generation in the periphery, the conversion of CD25-Foxp3+ cells into CD25 + Foxp 3 + cells could not be ruled out in these experiments as the naive cells were not depleted of Foxp $3+$ cells before adoptive transfer. ${ }^{57}$ Close on the heels of these findings, it was more definitively shown using genetic approaches that naive CD $4+\mathrm{T}$ cells in the periphery can indeed be induced to express Foxp3 under appropriate conditions and that the cells have suppressive function similar to nTregs. ${ }^{53,58-60}$ Using OVA-specific TCR transgenic mice crossed to scurfy mice that harbor a mutated Foxp3 gene, it was shown that a protocol of oral tolerance induced by supplying OVA in the drinking water of mice induced Tregs in the periphery that were important to 
control allergic sensitization. ${ }^{61}$ The findings in this study suggest that the induction of airway tolerance by delivery of aerosolized antigen ${ }^{50,52}$ most likely also involves iTregs, although the involvement of nTregs activated in a bystander manner cannot be ruled out.

Induction of tolerance by delivery of antigen through the airways $^{51,52}$ or the oral route $e^{53,61}$ almost completely thwarts the development of effector $\mathrm{T}$ cells if animals are subsequently immunized with antigen and adjuvant. Using TCR transgenic mice, it was shown that iTregs are also induced along with effector $\mathrm{T}$ cells after sensitization and antigen challenge and these Tregs limit the severity of allergic airway inflammation and also minimize its dissemination to extrapulmonary locations. ${ }^{61}$ The question that arises from the results of this study is whether the iTregs were induced during the challenge phase or not during priming in the inflammation model. This is because the presence of IL-4 and IL-6 during priming in the spleen should have inhibited Foxp3 induction. However, during challenge by inhaled antigen without adjuvant, low cytokine levels would have been conducive to iTreg generation in the lung-draining lymph nodes. In humans and in specific animal models, in which sensitization and challenge both occur by inhalation of allergen, iTreg generation may be compromised by the inhibitory effects of IL- 4 and IL-6. However, these same cytokines would permit polyclonal proliferation of nTregs as discussed below.

It has been suggested that TCR specificity guides peripheral Treg development that is also influenced by the location. ${ }^{62}$ Thus, the contribution of iTregs induced by allergens vs. nTregs in the regulation of allergic asthma would be dictated by both the allergen and the local microenvironment. In this regard, a possibility that can be entertained is that iTregs that regulate allergic airway inflammation are peripherally induced at sites other than the lung to be subsequently recruited by antigen-induced inflammation to the lung. A likely mucosal site for this is the gastrointestinal tract in which Tregs are required to maintain intestinal homeostasis by upholding tolerance to food antigens and gut microflora, the absence of which could lead to experimental colitis. ${ }^{63-66}$ This speculation is based on knowledge derived from various studies that show intestine and associated lymphoid tissue as a site for proliferation ${ }^{66}$ and induction of Foxp3 + Tregs from naive precursors, ${ }^{21,67}$ and the observations that changes in gut microflora ${ }^{68}$ and probiotic treatments influence airway hyperresponsiveness and allergies. ${ }^{69-71}$ When viewed in combination, it seems likely that the gut serves as a "hub" or "depot" for inducing Tregs, which then home to various sites of infection/inflammation to exert suppressive activity. The repertoire of these induced Tregs would be mainly governed by the nature of the intestinal microflora, the subtle changes in which could lead to susceptibility or resistance to a particular antigen locally or more distally in the lung. Needless to say, an interplay between genetics and the immune mechanisms would drive the net outcome in every individual. So, how do iTregs or nTregs elicit immune suppression?

The process of infectious tolerance was recently shown to involve Foxp $3+$ Tregs expressing membrane-bound TGF- $\beta$ coupled to latency-associated peptide. ${ }^{72}$ These membrane-bound
TGF- $\beta$ latency-associated peptide-expressing Tregs induced Foxp3 expression in naive Foxp3 - CD4 + T cells when stimulated by plate-bound anti-CD3, which in turn acquired suppressive function. ${ }^{72}$ Given that Tregs have been shown to inhibit the immunogenic potential of pulmonary DCs by downregulating expression of major histocompatibility complex class II and costimulatory molecules, ${ }^{54,55}$ an expanded population of Tregs expressing TGF- $\beta$ may also serve to downregulate DC function in both draining lymph nodes and the tissue. This raises the question of the involvement of antigen-specific Tregs in regulating allergic asthma. It is difficult to imagine that the large pool of Tregs that infiltrate the airways during allergic inflammation comprise only antigen-specific iTregs. Even if the process of infectious tolerance is operative in the induction and activation of many of these Tregs, a substantial fraction of the Tregs likely consists of polyclonal nTregs. Thus, in the first study that generated Tregs in vitro from naive CD $4+\mathrm{T}$ cells in the presence of TGF- $\beta$, the adoptive transfer of a polyclonal population of Tregs into mice was highly efficient in suppressing house dust miteinduced allergic airway inflammation. ${ }^{56}$ Another recent study of experimental asthma also suggests that suppression of allergic inflammation in the airways involves locally activated polyclonal Tregs. ${ }^{73}$ Activation of Tregs is important for efficient suppression as freshly isolated Tregs from naive mice have weak suppressive function, unless activated to boost their potency. ${ }^{74}$ Taken together, it seems reasonable to conclude that the most efficient Treg-mediated suppression of allergic asthma can be achieved by establishment of mucosal tolerance to a range of allergens in early life. This would involve induction of antigen-specific Tregs enhanced by the process of infectious tolerance that would last lifelong to limit generation of allergen-specific effector $\mathrm{T}$ cells. However, the potential to induce such Tregs would be less after antigen sensitization because of cytokine inhibition.

Any discussion on the efficiency of iTreg generation should also consider the context. For example, in one study, when CD4 + Foxp3 - T cells were adoptively transferred into transgenic mice with TCR specificity for myelin basic protein and the mice were subsequently immunized with myelin oligodendrocyte glycoprotein peptide to induce experimental autoimmune encephalomyelitis, de novo conversion of Foxp3 - to Foxp3+ cells was minimal in the draining lymph nodes. ${ }^{75}$ As this model is a driver of intense Th17 differentiation, it illustrates the point that specific pro-inflammatory cytokines produced in the lymph nodes exercise a strong influence on iTreg development. Somewhat conterintuitively, these same cytokines that block iTreg development promote the proliferation of nTregs and help maintain their Foxp3 expression. This would explain why in our study as well as in the experimental autoimmune encephalomyelitis and multiple other studies in humans and animals, Tregs can be found in large numbers at the site of inflammation. As can be concluded from the study of Lafaille et al. ${ }^{61}$ the Tregs that accumulate at the site of inflammation help to temper the inflammation as well as to contain it. Lastly, an important question that needs to be addressed in future studies is whether the efficiency of iTreg development is dissimilar in different lymph nodes. 
As discussed previously, there maybe a window of opportunity in early life to develop life-long tolerance to harmful antigens, such as allergens, through development of antigen-specific Tregs before sufficient maturation of the immune system and generation of effector T cells has taken place (Figure 1). ${ }^{31,32}$ Interestingly, a recent study of colorectal cancer patients has shown that Tregs specific to only a limited set of tumor-associated antigens control antitumor effector responses to the same set of antigens. ${ }^{76}$ Thus, knowledge of antigen specificity of Tregs in disease would undoubtedly be immensely helpful to promote antitumor responses or to suppress effector responses in allergic and autoimmune diseases.

\section{BLOCKADE OF TREG DEVELOPMENT BY} PRO-INFLAMMATORY CYTOKINES AND EXFOXP3 TREGS

It is clear that both Th2 and Tregs coexist at the site of allergic inflammation. ${ }^{61,77}$ Therefore, a logical question that arises is what effects the pro-inflammatory cytokines secreted by the Th2 cells exert on Tregs. We focus here on two cytokines, IL-6 and IL4, both of which promote Th2 but block Treg development. IL-6 also promotes Th17 development in combination with TGF$\beta .^{78-81}$ The IL-6 receptor exists in both membrane-bound and soluble forms (sIL-6R) and the complex of IL-6 with its soluble receptor upon interaction with gp130 expressed on cells induces downstream signaling in a process called IL-6 trans-signaling. ${ }^{82}$ sIL-6R is found in large quantities in chronic inflammatory diseases. The IL-6/sIL-6R complex has been associated with inhibition of development of CD4 + CD25 + Foxp3 + cells and also impairment of their suppressive function in models of asthma and inflammatory bowel disease. ${ }^{83,84}$ In T cells, loss of STAT3 (signal transducer and activator of transcription 3 ), which is activated by IL-6, upregulated Foxp3 expression. ${ }^{85}$ Thus, targeting IL-6 signaling should improve Treg-mediated suppression in asthma. IL-4-induced signaling in T cells promotes Th2 differentiation but inhibits Treg development. STAT6 is activated by IL-4 in naive CD 4 + T cells and upregulates GATA-3 expression, which is the master regulator of Th2 cell differentiation. ${ }^{86,87}$ Both STAT ${ }^{88}$ and GATA- $3^{89}$ can bind to the Foxp3 promoter to inhibit Foxp3 gene transcription. Together, the cytokines IL-4 and IL- 6 would not only drive T helper cell differentiation but would also block iTreg development.

As discussed above, it can be assumed that a large fraction of Tregs that accumulate in the airways during allergic inflammation are nTregs that are induced to proliferate and express CCR4 in the lung-draining lymph nodes, resulting in their recruitment to the site of inflammation. ${ }^{90}$ An additional level of complexity recently identified by us is that chronic STAT6 signaling in the effector cells imparts resistance to suppression by Tregs. ${ }^{77}$ Thus, although IL-4 promotes nTreg proliferation and maintains Foxp3 expression, Tregs are unable to completely block Th2 effector function in situ. The opposing actions of IL-4 and IL-6 on T helper vs. Treg development illustrate an important role of cytokines in regulating the dynamics of inflammation. At the same time a cytokine would allow $\mathrm{T}$ helper cell differentiation and induce resistance to Treg-mediated suppression, it would inhibit iTreg development and infectious tolerance. However, under these conditions, nTregs would actually be allowed to proliferate and traffic to the tissue as IL- 4 is a proliferative factor for already developed Tregs. ${ }^{77,91}$ This would ensure that when the effector response eventually contracts, the Tregs are poised to take over and restore homeostasis. In a similar manner, in sarcoidosis, a granulomatous disease of the lung driven by Th1 cells, spontaneous IL-2 secretion by lung effector T cells has been implicated in Treg expansion around the granulomas, ${ }^{92}$ which was also noted in the study of experimental autoimmune encephalomyelitis. ${ }^{75}$ The competing effects of IL-4 and IL- 2 on Tregs vs. T effector function likely determine the magnitude of the induced inflammation. Accumulation of a large pool of Tregs in the inflamed lung may also be undesirable in light of the recent unexpected finding that Tregs are susceptible to loss of Foxp3 at inflamed sites ${ }^{93,94}$ and that along with Foxp3 they coexpress transcription factors induced in effector T cells. ${ }^{95-97}$ Whether these factors promote the stability of Tregs will be interesting to determine in the future.

Recently, some unexpected features of Tregs have been identified. Tregs in inflamed tissues were shown to lose Foxp3 (resulting cells termed exFoxp3) and secrete pro-inflammatory cytokines. ${ }^{93,94}$ Second, Tregs were shown to express transcription factors characteristic of T helper cells such as T-bet and interferon regulatory factor 4 (IRF4). ${ }^{96,97}$ IRF4 promotes IL-4 gene expression in Th2 cells and T-bet is a Th1-specific transcription factor. It has been proposed that expression of specific effector T-cell transcription factors in Tregs helps limit the function of the effector T cell in which the same factor is expressed. ${ }^{95-97}$ The mechanism by which this is achieved is unclear. If this dual-expressing Treg then loses Foxp3 but retains the other transcription factor such as IRF4, it may cause expression of pro-inflammatory cytokines from that cell, as was observed for exFoxp3 cells recovered from different tissues of diabetic animals. ${ }^{93}$ It is, however, unclear whether such a cell would indeed be capable of producing all of the Th2 cytokines, as IRF 4 alone is not enough for the expression of Th2 cytokine genes. Given that both STAT6 and GATA-3, which are expressed specifically in Th2 cells, inhibit Foxp3 expression, ${ }^{88,89}$ it is unlikely that a Foxp $3+$ Treg would be replete with the full spectrum of Th2 factors. Tregs can coexpress T-bet and Foxp3, whereas retinoic acid-related orphan receptor- $\gamma \mathrm{t}$ and Foxp 3 have a reciprocal relationship. ${ }^{98-100}$ Therefore, loss of Foxp3 in Tregs in a model of diabetes might promote secretion of interferon- $\gamma$ or IL-17A. This, however, does not necessarily imply that Foxp3-deficient Tregs would behave as Th2 cells. Whether these would instead develop into Th17 cells in the context of allergic inflammation is an interesting possibility, given that IRF4 is also important for the Th17 phenotype and loss of Foxp3 may promote retinoic acid-related orphan receptor- $\gamma t$ expression. This is of significant concern as Tregs express CCR4, which is also expressed by Th2 cells, ${ }^{101}$ and thus the Tregs with lost Foxp3 would still coexist with Th2 cells at the site of inflammation. These exFoxp3 cells may secrete IL-17A to promote neutrophilic asthma, which is a characteristic of severe asthma. In fact, it may not be too far fetched to consider the possibility that retention of the exFoxp3 cell by virtue of CCR 4 expression in the lung, and stimulation 
by self antigen-derived peptides resulting in IL-17A secretion, is one of the recipes for the development of non-atopic/intrinsic asthma.

\section{MECHANISMS BY WHICHTREGS INHIBIT EFFECTORT- CELL FUNCTION IN ASTHMA}

As discussed above, the two molecules that have received the most attention with respect to Treg-mediated suppression of allergic airway inflammation are TGF- $\beta$ and IL-10. Our investigations showed that membrane-bound TGF- $\beta$ expressed by Tregs in mice tolerized by inhaled antigen ${ }^{52}$ activates Notch inducing expression of its downstream target gene Hes1 (hairy and enhancer of split 1) in naive CD4 + T cells..$^{51} \mathrm{Hes} 1$ is a potent repressor of gene expression. ${ }^{102,103}$ Simultaneous engagement of TCR, CD28, and Notch was shown to inhibit T-cell activation, which was associated with upregulation of Hes1 expression. ${ }^{104}$ Given that membrane-bound TGF- $\beta$, originally identified on activated Tregs, ${ }^{105}$ has now been implicated in infectious tolerance, ${ }^{72}$ Hes 1 may have an important role in the induction and/or stabilization of Foxp 3 expression in the CD4 + T cell destined to become an iTreg. Indeed, Notch activation in Tregs was recently shown to promote Foxp3 expression and stabilize Tregs in vivo. ${ }^{106}$ Figure 2 merges all of these concepts in the context of mucosal tolerance. iTreg development is at a disad- vantage during allergen-induced $\mathrm{T}$ helper cell differentiation that promotes nTreg proliferation (Figure 2).

Although Notch activation has been also associated with T helper cell differentiation, ${ }^{107}$ it is likely that the strength of Notch ligation and duration of expression of its target genes such as Hes1 differs when T cells are activated vs. when they are suppressed. IL-10 induces T cell anergy and it is believed to be due to inhibition of costimulation of T cells. ${ }^{108,109} \mathrm{IL}-10$ also has effects on Ig isotypes promoting IgG4 and inhibiting IgE switching. ${ }^{110}$ With regard to other mechanisms used by Tregs in curbing asthma, a recent study showed that Treg-expressed OX40 upon ligation of OX40L on mast cells inhibited their degranulation. ${ }^{111}$ Although IDO (indoleamine 2, 3 dioxygenase) has been associated with Treg-mediated suppression, ${ }^{112}$ our studies and that of others suggest an involvement of IDO in promotion of Th2 responses using the model allergen, OVA. ${ }^{13,114}$ In mice infected with Aspergillus fumigatus, a fungus associated with development of allergic bronchopulmonary aspergillosis, a role for IDO in control of fungal burden, allergic response, and Treg function late in infection was noted. ${ }^{115}$ More studies are needed in different animal models and in humans to elucidate the role of IDO in regulating effector responses in the airways.

With the demonstration of a specific role for Treg-expressed CTLA-4 (cytotoxic T-lymphocyte antigen 4) in suppressive

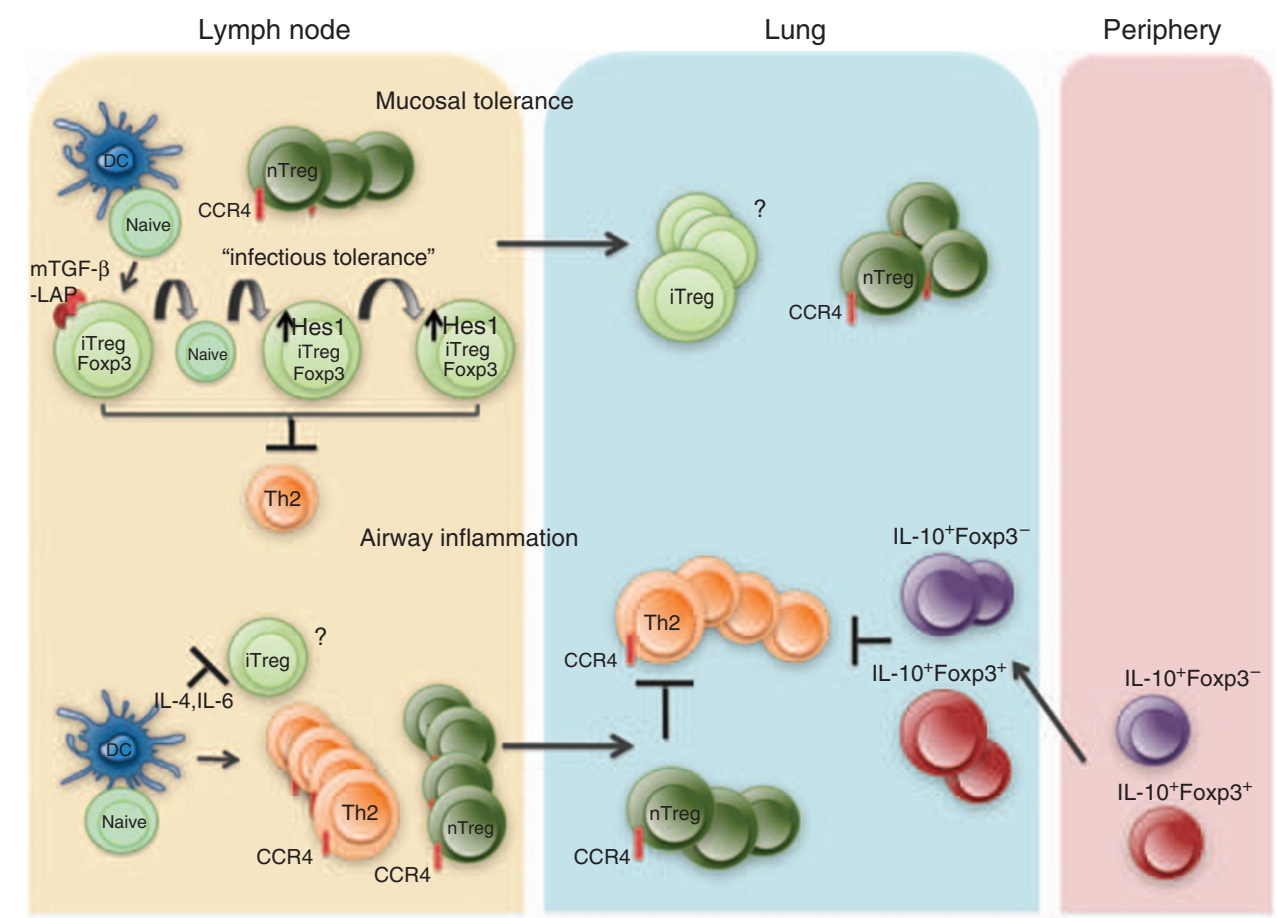

Figure 2 Mucosal tolerance favors inducible/adaptive Treg (iTreg) development in lung-draining lymph nodes that have free reign in tolerance but compete with $n$ Tregs during inflammation. Latency-associated peptide (LAP)-associated membrane-bound transforming growth factor- $\beta$ (mTGF- $\beta$ ) on iTregs exerts an effect through infectious tolerance to increase its pool size. ${ }^{72}$ mTGF- $\beta$ induces Notch activation and upregulation of the downstream repressor Hes1 (hairy and enhancer of split 1) in naive CD4 + T cells. ${ }^{51}$ Hes1 has been shown to stabilize Foxp3 expression in Tregs. ${ }^{106}$ The iTregs efficiently suppress effector cell development (shown is Th2) in antigen-tolerized animals. ${ }^{51-53,61}$ In allergen-sensitized animals, the cytokines interleukin (IL)- 4 and IL-6 released during priming events suppress Treg induction. ${ }^{83,88,89,220}$ However, the same cytokines promote $n$ Treg proliferation while inducing Th2 differentiation ${ }^{77,83,220}$ (Th17 cells are also induced by allergens). The Th2 cells and $n$ Tregs traffic to the tissue in recall response to inhaled allergen in which they downmodulate costimulatory molecules on dendritic cells (DCs) ${ }^{54,55}$ (not shown). If priming occurs at a distant site (skin, spleen), IL-10-expressing Tregs are favored, ${ }^{47-49,55}$ which are recruited to the lung in response to allergen challenge to suppress effector T-cell functions. 
Table 2 Treg-mediated suppression of effector CD4 + T-cell induction or function in allergic disease

\begin{tabular}{lll}
\hline & \multicolumn{2}{c}{ Regulation of effector T-cell } \\
\cline { 2 - 3 } Treg type & Induction & Function \\
\hline Foxp3 + & Ref. ${ }^{29,51-53,61}$ & Ref. \\
& & $54,55,73,77,83,97,118$ \\
Foxp3 - & Ref. ${ }^{43,45,46}$ & Ref. ${ }^{47-49}$ \\
\hline
\end{tabular}

function through downregulation of CD80/CD86 on DCs, ${ }^{116}$ CTLA-4 may have a key role in inhibition of expression of costimulatory molecules by lung DCs in allergic airway inflammation. ${ }^{54,55}$ Another cytokine, IL-35, secreted by Tregs has been implicated in the suppressive effects of these cells. ${ }^{117}$ In a recent study, a complex of IL-2:anti-IL-2 monoclonal antibody was administered into mice sensitized through the intraperitoneal route with Schistosome antigen or OVA/alum and subsequently challenged with antigen. ${ }^{118}$ The regimen of cytokine-antibody complex diminished allergic airways disease and required IL-10producing Tregs. ${ }^{118}$ Interestingly, an increase in IL-35 production was observed in IL-10-competent but not deficient animals in this study. ${ }^{118}$ This observation was in line with previous findings that observed IL-10-promoting effects of IL-35. Table 2 is a summary of the literature that associated either Foxp3 + or Foxp3 Tregs with either induction of effector $\mathrm{T}$ cells or their function.

\section{MICRORNA CONTROL OFTREGS}

The role of microRNAs in Treg function in the periphery is not sufficiently understood at the present time. Treg-specific deletion of Dicer, the processing enzyme for precursors of microRNAs, had only minimal effect on Treg development, seeding, proliferation, and survival in the periphery. However, splenomegaly and lymphadenopathy was developed in $>5$-week-old mice and they died at 6-8 weeks of age. ${ }^{119,120}$ The role of a specific microRNA, miR-155, in Treg development and function

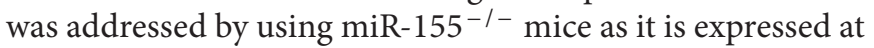
higher levels in nTregs when compared with that in double-positive thymocytes or $\mathrm{CD} 4+\mathrm{T}$ cells. Although the frequency and

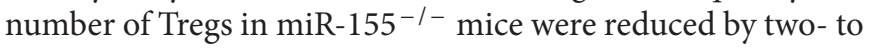
threefold in the thymus and spleen, their suppressive function was not impaired. ${ }^{121,122}$ miR-155-deficient mice show a bias toward Th2 development and produce more IL-10-producing CD4 + T cells. ${ }^{123,124}$ Thus, generation of IL-10-producing Tregs may involve downregulation of miR-155 expression.

\section{USE OF VARIOUS TREATMENTS TO EXPANDTREGS INTHE CONTEXT OF ASTHMA}

\section{Instability of in vitro-generated Tregs}

All of the compelling evidence in the literature suggests that Tregs are ideal candidates for developing effective therapies to treat diseases such as asthma. We have already discussed about the possibility of developing allergen-specific Tregs in neonates for life-long protection from atopic asthma (Figure 1). What about treating asthmatics who already have allergenspecific effector cells? One possible strategy that has been most studied is Treg cell transfer-mediated immunotherapy in which antigen-specific Treg cells are expanded/induced in vitro and transferred back into the host. The major hurdles in expanding the existing antigen-specific cells from the repertoire were (i) low frequency of antigen-specific Treg cells, especially in tissues, (ii) poor proliferation in vitro, ${ }^{125,126}$ and (iii) expansion of contaminating effector cells in the presence of IL-2. ${ }^{126,127}$ Given that polyclonal Tregs have been also shown to exercise suppressive effects, ${ }^{56}$ a possibility exists in using in vitro-expanded polyclonal Tregs. However, it was shown that in vitro-generated human Foxp3 + CD4 + T cells lack suppressive function and produce effector cytokines. ${ }^{128}$ In addition, in the absence of exogenous TGF- $\beta$, the majority of in vitro-induced Tregs lose their Foxp3 expression. ${ }^{129,130}$ As stable Foxp3 expression is quintessential for the maintenance, sustenance, and suppressive functions of Treg cells, ${ }^{131}$ the efficacy of TGF- $\beta$-induced Foxp $3+$ CD $4+$ T cells in comparison to nTregs is doubtful. The following section discusses the role of various agents that have been shown to promote Treg generation and/or function and the relevance of these findings in suppressing allergic responses in the lung.

\section{Retinoic acid}

In vitro, TGF- $\beta$-induced conversion to Foxp $3+$ Tregs has been shown to be enhanced and stabilized by the vitamin A metabolite, retinoic acid. ${ }^{67,88,132-138}$ Retinoic acid was shown to induce de novo conversion to Treg cells even at high levels of costimulation, suggesting that by some unknown mechanism, retinoic acid overrides the inhibitory effect of costimulation on the induction of FoxP3 expression. ${ }^{138}$ Recently, it was shown that promotion of Foxp 3 + iTregs by retinoic acid is not due to its direct effect on the responder cells but because of inhibition of cytokine production by CD $44^{\text {hi }}$ effector memory T cells. ${ }^{135}$

Similar synergistic relationship between TGF- $\beta$ and retinoic acid in inducing, expanding, and maintaining Tregs has been observed in vivo. ${ }^{135,139}$ To understand the function of retinoic acid in the generation of Tregs in vivo, we need to understand its metabolism. Retinoic acid production from retinol is a sequential process that ultimately involves retinal to retinoic acid conversion by retinal dehydrogenases (RALDH). Among the various biologically active retinoids, all-trans retinoic acid (ATRA) is the most potent known metabolite. ${ }^{140}$ Extensive research has characterized ATRA as the physiological ligand for the retinoic acid receptor family of nuclear hormone receptors. ${ }^{141,142}$ Multiple studies have recently shown production of retinoic acid or expression of retinal dehydrogenases (RALDH1 and/or RALDH2) in different cell types in the gut promoting Treg development. Even though both vitamin A intake and its metabolism to retinoic acid have been shown to be essential in lung development and maintaining pulmonary homeostasis, the cellular participants responsible for generating retinoic acid in the lungs are still unclear. In one study, ${ }^{143}$ isolated lung lipid interstitial cells were found to be capable of converting all-trans retinol to an acidic retinoid with properties that are similar and possibly identical to those of ATRA. Most of the retinoic acid produced by the lipid interstitial cells was secreted in the lung alveoli, in which it could be taken up by other lung cells to exert immunodulatory effects. Recently, airway epithelial 
cell-expressed MMP-7 (matrix metallopeptidase 7) was shown to regulate RALDH1, which promoted the development of immunosuppressive Tregs causing attenuation of allergic responses. ${ }^{144}$ This finding was in contrast to reports that showed exacerbated allergic responses after in vivo administration of ATRA. ${ }^{145,146}$ It should be noted that in the steady state, retinoic acid is bound to albumin and circulates in plasma in nanomolar concentrations with a typical half-life, in rodents, of less $<1 \mathrm{~h} .{ }^{147}$ Most studies that have shown the biological activities and importance of retinoic acid in regulating immune responses have used supraphysiological concentrations added either to cultured cells or, less frequently, administered to animals in vivo. The dose of ATRA used in the in vivo studies has been variable, depending on the mouse model used. Although such experiments have shown the potential scope of retinoic acid-mediated induction of Tregs and suppression of inflammatory responses in the gut, the suppressive effect of retinoic acid in the lung is clearly not uniformly observed. The reasons for the divergent results need to be determined in future studies, especially because there are studies showing Th2inducing potential of retinoic acid through retinoic acid-retinoic acid receptor-mediated signaling. ${ }^{145,146,148-150}$ Iwata et al. ${ }^{150}$ suggest that this effect of retinoic acid on Th2 differentiation is stage dependent and retinoic acid enhances Th2 responses only if it is added in initial stages of $\mathrm{T}$ helper cell differentiation.

\section{Vitamin D}

Independently, several investigations have shown a direct relationship between vitamin $\mathrm{D}$ and asthma. ${ }^{151-154}$ 1,25-dihydroxyvitamin $\mathrm{D} 3[1,25(\mathrm{OH}) 2 \mathrm{D} 3)]$, the active metabolite of vitamin D3, is a lypophilic molecule that exerts its actions through a nuclear receptor, the VitD3 receptor (VDR). ${ }^{155-157}$ A number of recent studies have consistently shown the ability of vitamin D3 and VDR agonists to exert an effect as strong immunosuppressors. ${ }^{158,159}$ Vitamin D3 has also been shown to directly enhance suppressive function of Tregs. ${ }^{160}$ As an immunosuppressant, 1,25(OH) 2 D3 has been implicated in inhibition of Th1 differentiation, as studied in Th1-dominated animal models. ${ }^{158,161,162}$ Interestingly, Vitamin D3-VDR signaling and VDR agonists have been shown to either promote or inhibit proliferation and differentiation of Th2 cells. ${ }^{154,158,163-165}$ Such opposite effects of vitamin D3 in regulating Th2 2 cell responses were also observed in models of experimental allergic asthma, in which $1,25(\mathrm{OH}) 2 \mathrm{D} 3$ treatment was either beneficial, ${ }^{153,154,166}$ without effect, ${ }^{167}$ or deleterious. ${ }^{153,165,167}$ As with retinoic acid, the discrepancies in the findings could be due to variations in dose, route of administration, duration of exposure, and the choice of experimental model.

\section{Allergen-specific immunotherapy}

Another strategy to expand antigen-specific Treg cell repertoire in vivo involves exposure to low doses of antigen without adjuvants. Such protocols induce antigen-specific immunosuppression and are designated allergen-specific immunotherapy (SIT) pioneered by Noon in 1911. ${ }^{168,169}$ SIT involves the administration (usually subcutaneous) of increasing doses of allergen to achieve hyporesponsiveness to it. Various effects of SIT have been documented, including induction of Tregs secreting IL-10 and TGF- $\beta{ }^{49,170-173}$ In the clinical setting, SIT is the only treatment that induces specific Treg cells in human subjects. ${ }^{174}$ Although administration of specific allergens has been shown to be effective in rhinitis ${ }^{175}$ and insect venom allergy, ${ }^{176,177}$ the role of this intervention in allergic asthma remains controversial. ${ }^{178-}$ ${ }^{180}$ SIT has proven efficacious in treating mild asthma, ${ }^{181}$ as well as for preventing the progression to asthma in patients suffering from rhinitis. ${ }^{182,183}$ However, it is not yet recommended for treatment of moderate-to-severe asthma. ${ }^{184}$ Furthermore, the major drawbacks of this treatment are the risks for inducing rare but life-threatening systemic reactions mediated by IgE in patients requiring long-term administration of SIT. ${ }^{179,185}$

Strategies to improve the safety of allergen immunotherapy were initially focused on reducing the allergenicity of the preparation by using modified allergens (allergoids), novel adjuvants, and use of alternate routes of administration. ${ }^{186-188}$ Along these lines, peptide immunotherapy, involving use of peptide fragments from allergens corresponding to T-cell epitopes to induce immunologic tolerance, has met with success in experimental models of allergic disease. ${ }^{189}$ Peptide immunotherapy is an advantage over SIT as it does not result in adverse IgE responses because of their relatively small size and therefore inability to cross-link allergen-specific IgE. ${ }^{190,191}$ Peptide treatment suppressed allergen-specific T-cell proliferation and production of cytokines IL-4, IL-13, and interferon- $\gamma$ but induced IL-10 production ${ }^{192-194}$ and IL-10-dependent functional Tregs. ${ }^{195}$ Because of the successful induction of tolerance and suppression of inflammatory responses, peptide immunotherapy has emerged as an ideal alternative to SIT. Currently, clinical data are available for two allergens that have been targeted with this approach, which are the cat allergen Fel d $1^{192,193,196}$ and the bee venom allergen Apim1 (phospholipase A2). ${ }^{176,197,198}$ Despite accumulation of considerable evidence showing a beneficial role of allergen-derived peptide immunotherapy, there have been instances in which late asthmatic reactions followed by bronchial hyperresponsvieness to the peptides were reported in patients. ${ }^{12}$ These adverse effects could be related to peptide dose and immunogenicity. Further attempts are being made to finetune the existing protocols that can provide maximum benefit at lower doses of peptides. Recently, linked epitope suppression, a key immunologic mechanism of peptide immunotherapy was shown, in which treatment with selected epitopes from a single allergen, Fel d 1, resulted in suppression of immune responses to other "linked" epitopes within the same molecule. ${ }^{49}$ Additional evaluation of appropriate immunogenic peptides from different allergens would increase the applicability of peptide immunotherapy to severe asthmatics.

\section{Corticosteroids and rapamycin}

Corticosteroids or glucocorticoids are by far the most routinely used and most effective anti-inflammatory therapy for both acute and chronic allergic diseases and asthma. Among the various mechanisms identified for glucocorticoid-mediated suppression, promotion of Foxp3 expression and suppressive function in CD4 + T cells was also noted. ${ }^{199}$ The increase in Foxp3 mRNA subsequent to glucocorticoid treatment, although 
transient, was tightly correlated with increase in IL-10 mRNA, although the expression of TGF- $\beta$ remained unchanged. Similar increases in IL-10 synthesis and reduction in pro-inflammatory cytokine production subsequent to inhalation of corticosteroids have been reported in asthma patients. ${ }^{200,201}$ A more conclusive study recently showed that an inhaled corticosteroid could reverse the observed poor numbers of CD4+CD25 hi cells in the bronchoalveolar lavage fluid of asthmatic children. ${ }^{202}$ However, treatment with corticosteroids (dexamethasone) has been also shown to inhibit induction of IL-10 and development of Tregs. ${ }^{203}$ The researchers have cautioned against long-term use of corticosteroids, especially in treating chronic conditions. They suggest that the inhibitory effect of corticosteroids on Treg development may cause excessive pro-inflammatory responses when the individual is re-exposed to the allergen. In contrast, Barrat et al. ${ }^{158,159}$ have shown that dexamethasone, in synergism with $1 \alpha, 25$-dihydroxyvitamin D3 (calcitriol), the active form of vitamin D, directly induces IL-10 secreting regulatory $\mathrm{T}$ cells ( $\operatorname{Tr} 1$ cells).

Rapamycin, a small molecule drug, chemically defined as a macrocyclic lactone, routinely used as an immunosuppressive drug in organ transplantation, has been found to promote in vitro expansion of both murine $e^{204,205}$ and human Tregs, ${ }^{206-209}$ which could be highly significant in generating clinically relevant quantities of Tregs. ${ }^{210}$ The mechanisms underlying the selective and preferential expansion of Tregs and maintenance of suppressive activity in the presence of rapamycin are unclear. Some studies attribute it to selective survival advantage, ${ }^{209}$ whereas others show induction of Treg-like phenotype in T effector cells in the presence of rapamycin. ${ }^{21-213}$ Recently, a study showed that the molecule Pim2, which is selectively upregulated in Foxp3-expressing cells, is responsible for providing the survival signal. ${ }^{214}$ This preferential expansion or survival of Treg cells has also been shown after in vivo administration of rapamycin. ${ }^{215}$ In independent studies, rapamycin has been shown to inhibit asthma and airway remodeling in experimental models, ${ }^{216-219}$ thereby highlighting another drug that can be used to expand antigen/allergen-specific Tregs.

\section{CONCLUDING REMARKS}

Both human and animal studies show that Tregs are regulators of allergic airways disease. There does not seem to be a unique mechanism that underlies their regulatory function in this disease as has been realized in other diseases as well. It is clear that thymus-derived nTregs are not the only Tregs that are involved in suppression of allergic disease. iTregs have been identified in early life and the challenge in future years is to capitalize on this realization to induce allergen-specific Tregs. However, multiple issues and controversies need to be resolved before Treg cell-based immunotherapy becomes routine practice. More knowledge about the molecular mechanisms driving Treg cell proliferation, activation, and survival is required. Investigations pertaining to stability of Foxp3 in ex vivo-manipulated and later adoptively transferred induced/expanded Treg population is critical, especially in light of the concept of exFoxp3 cells. ${ }^{93,94}$ Given the intense interest in these cells in the field of immunology as a whole, it is hoped that the basic knowledge gained about these cells would translate into dependable Treg-mediated patient care in the not too distant future.

\section{ACKNOWLEDGMENTS}

We thank Stephanie L. Poe for excellent assistance with the artwork. This work was supported by US National Institutes of Health grants HL 077430 and Al 048927 (to A.R), HL060207 (to P.R.), and HL 084932 (to A.R. and P.R.). We regret inadvertent omission of additional relevant publications.

\section{DISCLOSURE}

The authors declared no conflict of interest.

(C) 2010 Society for Mucosal Immunology

\section{REFERENCES}

1. Metzger, W.J. et al. Local allergen challenge and bronchoalveolar lavage of allergic asthmatic lungs: description of the model and local airway inflammation. Am. Rev. Respir. Dis. 135, 433-440 (1987).

2. Gavett, S.H., Chen, X., Finkelman, F. \& Wills-Karp, M. Depletion of murine $\mathrm{CD} 4^{+} \mathrm{T}$ lymphocytes prevents antigen-induced airway hyperreactivity and pulmonary eosinophilia. Am. J. Respir. Cell Mol. Biol. 10, 587-593 (1994)

3. Corrigan, C.J., Hartnell, A. \& Kay, A.B. T lymphocyte activation in acute severe asthma. Lancet 1, 1129-1132 (1988).

4. Wierenga, E.A. et al. Evidence for compartmentalization of functional subsets of CD2+ T lymphocytes in atopic subjects. J. Immunol. 144, 4651-4656 (1990).

5. Hamid, Q. et al. Expression of mRNA for interleukin-5 in mucosal bronchial biopsies from asthma. J. Clin. Invest. 87, 1541-1546 (1991).

6. Robinson, D.S. et al. Predominant $\mathrm{T}_{\mathrm{H} 2}$-like bronchoalveolar Tlymphocyte population in atopic asthma. N. Engl. J. Med. 326, 298-304 (1992).

7. Kay, A.B. et al. Messenger RNA expression of the cytokine gene cluster IL-3, IL-4, IL-5 and GM-CSF in allergen-induced late-phase cutaneous reactions in atopic subjects. J. Exp. Med. 173, 775-778 (1991).

8. Barrett, N.A. \& Austen, K.F. Innate cells and T helper 2 cell immunity in airway inflammation. Immunity 31, 425-437 (2009).

9. Barnes, P.J. New molecular targets for the treatment of neutrophilic diseases. J. Allergy Clin. Immunol. 119, 1055-1062; quiz 1063-1054 (2007).

10. Bullens, D.M. et al. IL-17 mRNA in sputum of asthmatic patients: linking T cell driven inflammation and granulocytic influx? Respir. Res. 7, 135 (2006).

11. Hellings, P.W. et al. Interleukin-17 orchestrates the granulocyte influx into airways after allergen inhalation in a mouse model of allergic asthma. Am. J. Respir. Cell Mol. Biol. 28, 42-50 (2003).

12. Molet, S. et al. IL-17 is increased in asthmatic airways and induces human bronchial fibroblasts to produce cytokines. J. Allergy Clin. Immunol. 108, 430-438 (2001).

13. McKinley, L. et al. TH17 cells mediate steroid-resistant airway inflammation and airway hyperresponsiveness in mice. J. Immunol. 181, 4089-4097 (2008).

14. Owen, R.D. Immunogenetic consequences of vascular anastomoses between bovine twins. Science 102, 400-401 (1945).

15. Billingham, R.E., Brent, L. \& Medawar, P.B. Actively acquired tolerance of foreign cells. Nature 172, 603-606 (1953).

16. Strachan, D.P. Hay fever, hygiene, and household size. BMJ 299, 12591260 (1989).

17. van den Biggelaar, A.H. et al. Decreased atopy in children infected with Schistosoma haematobium: a role for parasite-induced interleukin-10. Lancet 356, 1723-1727 (2000)

18. Yazdanbakhsh, M., Kremsner, P.G. \& van Ree, R. Allergy, parasites, and the hygiene hypothesis. Science 296, 490-494 (2002).

19. Wilson, M.S. et al. Suppression of allergic airway inflammation by helminth-induced regulatory T cells. J. Exp. Med. 202, 1199-1212 (2005).

20. McGuirk, P. \& Mills, K.H. Pathogen-specific regulatory T cells provoke a shift in the Th1/Th2 paradigm in immunity to infectious diseases. Trends Immunol. 23, 450-455 (2002).

21. Coombes, J.L. et al. A functionally specialized population of mucosal CD103+ DCs induces Foxp3+ regulatory T cells via a TGF-beta and 
retinoic acid-dependent mechanism. J. Exp. Med. 204, 1757-1764 (2007).

22. Jankovic, D. et al. Conventional T-bet(+)Foxp3(-) Th1 cells are the major source of host-protective regulatory $\mathrm{IL}-10$ during intracellular protozoan infection. J. Exp. Med. 204, 273-283 (2007).

23. Kursar, M. et al. Cutting edge: regulatory T cells prevent efficient clearance of Mycobacterium tuberculosis. J. Immunol. 178, 2661-2665 (2007).

24. Berg, D.J. et al. Enterocolitis and colon cancer in interleukin-10-deficient mice are associated with aberrant cytokine production and CD4(+) TH1like responses. J. Clin. Invest. 98, 1010-1020 (1996).

25. Kuhn, R., Lohler, J., Rennick, D., Rajewsky, K. \& Muller, W. Interleukin10-deficient mice develop chronic enterocolitis. Cell 75, 263-274 (1993).

26. Li, M.O., Sanjabi, S. \& Flavell, R.A. Transforming growth factor-beta controls development, homeostasis, and tolerance of T cells by regulatory T cell-dependent and -independent mechanisms. Immunity 25, 455-471 (2006).

27. Dutta, P. \& Burlingham, W.J. Tolerance to noninherited maternal antigens in mice and humans. Curr. Opin. Organ Transplant 14, 439-447 (2009).

28. Mold, J.E. et al. Maternal alloantigens promote the development of tolerogenic fetal regulatory T cells in utero. Science 322, 1562-1565 (2008).

29. Verhasselt, $\mathrm{V}$. et al. Breast milk-mediated transfer of an antigen induces tolerance and protection from allergic asthma. Nat. Med. 14, 170-175 (2008).

30. Polte, T. \& Hansen, G. Maternal tolerance achieved during pregnancy is transferred to the offspring via breast milk and persistently protects the offspring from allergic asthma. Clin. Exp. Allergy 38, 1950-1958 (2008).

31. Holt, P.G., Strickland, D.H., Wikstrom, M.E. \& Jahnsen, F.L. Regulation of immunological homeostasis in the respiratory tract. Nat. Rev. Immunol. 8, 142-152 (2008).

32. Sly, P.D. et al. Early identification of atopy in the prediction of persistent asthma in children. Lancet 372, 1100-1106 (2008).

33. Torgerson, T.R. \& Ochs, H.D. Regulatory T cells in primary immunodeficiency diseases. Curr. Opin. Allergy Clin. Immunol. 7, 515521 (2007)

34. Groux, H. et al. A CD4+ T-cell subset inhibits antigen-specific T-cell responses and prevents colitis. Nature 389, 737-742 (1997).

35. Bennett, C.L. et al. The immune dysregulation, polyendocrinopathy, enteropathy, $X$-linked syndrome (IPEX) is caused by mutations of FOXP3. Nat. Genet. 27, 20-21 (2001).

36. Torgerson, T.R. \& Ochs, H.D. Immune dysregulation, polyendocrinopathy, enteropathy, X-linked: forkhead box protein 3 mutations and lack of regulatory T cells. J. Allergy Clin. Immunol. 120, 744-750; quiz 751-742 (2007).

37. Gambineri, E., Torgerson, T.R. \& Ochs, H.D. Immune dysregulation, polyendocrinopathy, enteropathy, and X-linked inheritance (IPEX), a syndrome of systemic autoimmunity caused by mutations of FOXP3, a critical regulator of T-cell homeostasis. Curr. Opin. Rheumatol. 15, 430435 (2003).

38. Zuidgeest, M.G. et al. Prescription of respiratory medication without an asthma diagnosis in children: a population based study. BMC Health Serv. Res. 8, 16 (2008).

39. Gambineri, E. et al. Clinical and molecular profile of a new series of patients with immune dysregulation, polyendocrinopathy, enteropathy, $X$-linked syndrome: inconsistent correlation between forkhead box protein 3 expression and disease severity. J. Allergy Clin. Immunol. 122, 1105-1112.e1 (2008).

40. Caudy, A.A., Reddy, S.T., Chatila, T., Atkinson, J.P. \& Verbsky, J.W. CD25 deficiency causes an immune dysregulation, polyendocrinopathy, enteropathy, X-linked-like syndrome, and defective IL-10 expression from CD4 lymphocytes. J. Allergy Clin. Immunol. 119, 482-487 (2007).

41. Sakaguchi, S., Yamaguchi, T., Nomura, T. \& Ono, M. Regulatory T cells and immune tolerance. Cell 133, 775-787 (2008).

42. Akdis, M. et al. Immune responses in healthy and allergic individuals are characterized by a fine balance between allergen-specific T regulatory 1 and T helper 2 cells. J. Exp. Med. 199, 1567-1575 (2004).

43. Meiler, F. et al. In vivo switch to IL-10-secreting T regulatory cells in high dose allergen exposure. J. Exp. Med. 205, 2887-2898 (2008).

44. Ito, T. et al. Two functional subsets of FOXP3+ regulatory T cells in human thymus and periphery. Immunity 28, 870-880 (2008).

45. Akbari, O., DeKruyff, R.H. \& Umetsu, D.T. Pulmonary dendritic cells producing IL-10 mediate tolerance induced by respiratory exposure to antigen. Nat. Immunol. 2, 725-731 (2001).
46. Akbari, O. et al. Antigen-specific regulatory T cells develop via the ICOSICOS-ligand pathway and inhibit allergen-induced airway hyperreactivity. Nat. Med. 8, 1024-1032 (2002).

47. Kearley, J., Barker, J.E., Robinson, D.S. \& Lloyd, C.M. Resolution of airway inflammation and hyperreactivity after in vivo transfer of CD4+CD25+ regulatory T cells is interleukin 10 dependent. J. Exp. Med. 202, 1539-1547 (2005).

48. Rubtsov, Y.P. et al. Regulatory T cell-derived interleukin-10 limits inflammation at environmental interfaces. Immunity 28, 546-558 (2008).

49. Campbell, J.D. et al. Peptide immunotherapy in allergic asthma generates IL-10-dependent immunological tolerance associated with linked epitope suppression. J. Exp. Med. 206, 1535-1547 (2009).

50. McMenamin, C., Pimm, C., McKersey, M. \& Holt, P.G. Regulation of IgE responses to inhaled antigen in mice by antigen- specific gamma delta $T$ cells. Science 265, 1869-1871 (1994).

51. Ostroukhova, M. et al. Treg-mediated immunosuppression involves activation of the Notch-HES1 axis by membrane-bound TGF-beta. J. Clin. Invest. 116, 996-1004 (2006).

52. Ostroukhova, M. et al. Tolerance induced by inhaled antigen involves CD4(+) T cells expressing membrane-bound TGF-beta and FOXP3. J. Clin. Invest. 114, 28-38 (2004).

53. Mucida, D. et al. Oral tolerance in the absence of naturally occurring Tregs. J. Clin. Invest. 115, 1923-1933 (2005).

54. Lewkowich, I.P. et al. CD4+CD25+ T cells protect against experimentally induced asthma and alter pulmonary dendritic cell phenotype and function. J. Exp. Med. 202, 1549-1561 (2005).

55. Strickland, D.H. et al. Reversal of airway hyperresponsiveness by induction of airway mucosal CD4+CD25+ regulatory T cells. J. Exp. Med. 203, 2649-2660 (2006).

56. Chen, W. et al. Conversion of peripheral CD4+CD25 - naive T cells to CD4+CD25+ regulatory T cells by TGF-beta induction of transcription factor Foxp3. J. Exp. Med. 198, 1875-1886 (2003).

57. Curotto de Lafaille, M.A., Lino, A.C., Kutchukhidze, N. \& Lafaille, J.J. CD25 - T cells generate CD25+Foxp3+ regulatory T cells by peripheral expansion. J. Immunol. 173, 7259-7268 (2004).

58. Apostolou, I. \& von Boehmer, H. In vivo instruction of suppressor commitment in naive T cells. J. Exp. Med. 199, 1401-1408 (2004).

59. Cobbold, S.P. et al. Induction of foxP3+ regulatory T cells in the periphery of T cell receptor transgenic mice tolerized to transplants. J. Immunol. 172, 6003-6010 (2004).

60. Kretschmer, K. et al. Inducing and expanding regulatory $T$ cell populations by foreign antigen. Nat. Immunol. 6, 1219-1227 (2005).

61. Curotto de Lafaille, M.A. et al. Adaptive Foxp3+ regulatory T celldependent and -independent control of allergic inflammation. Immunity 29, 114-126 (2008).

62. Lathrop, S.K., Santacruz, N.A., Pham, D., Luo, J. \& Hsieh, C.S. Antigenspecific peripheral shaping of the natural regulatory T cell population. J. Exp. Med. 205, 3105-3117 (2008).

63. Aranda, R. et al. Analysis of intestinal lymphocytes in mouse colitis mediated by transfer of CD4+, CD45RBhigh T cells to SCID recipients. J. Immunol. 158, 3464-3473 (1997).

64. Powrie, F., Leach, M.W., Mauze, S., Caddle, L.B. \& Coffman, R.L. Phenotypically distinct subsets of CD4+ T cells induce or protect from chronic intestinal inflammation in C. B-17 scid mice. Int. Immunol. 5, 1461-1471 (1993).

65. Izcue, A., Coombes, J.L. \& Powrie, F. Regulatory T cells suppress systemic and mucosal immune activation to control intestinal inflammation. Immunol. Rev. 212, 256-271 (2006).

66. Uhlig, H.H. et al. Characterization of Foxp3+CD4+CD25+ and IL-10secreting CD4+CD25+ T cells during cure of colitis. J. Immunol. 177, 5852-5860 (2006).

67. Sun, C.M. et al. Small intestine lamina propria dendritic cells promote de novo generation of Foxp3 T reg cells via retinoic acid. J. Exp. Med. 204, 1775-1785 (2007).

68. Noverr, M.C., Falkowski, N.R., McDonald, R.A., McKenzie, A.N. \& Huffnagle, G.B. Development of allergic airway disease in mice following antibiotic therapy and fungal microbiota increase: role of host genetics, antigen, and interleukin-13. Infect. Immun. 73, 30-38 (2005).

69. Hisbergues, M. et al. In vivo and in vitro immunomodulation of Der $\mathrm{p} 1$ allergen-specific response by Lactobacillus plantarum bacteria. Clin. Exp. Allergy 37, 1286-1295 (2007).

70. Feleszko, W. et al. Probiotic-induced suppression of allergic sensitization and airway inflammation is associated with an increase of T regulatory- 
dependent mechanisms in a murine model of asthma. Clin. Exp. Allergy 37, 498-505 (2007).

71. Karimi, K., Inman, M.D., Bienenstock, J. \& Forsythe, P. Lactobacillus reuteri-induced regulatory $T$ cells protect against an allergic airway response in mice. Am. J. Respir. Crit. Care Med. 179, 186-193 (2009).

72. Andersson, J. et al. CD4+ FoxP3+ regulatory T cells confer infectious tolerance in a TGF-beta-dependent manner. J. Exp. Med. 205, 19751981 (2008).

73. Joetham, A. et al. Naturally occurring lung CD4(+)CD25(+) T cell regulation of airway allergic responses depends on IL-10 induction of TGF-beta. J. Immunol. 178, 1433-1442 (2007).

74. Thornton, A.M. \& Shevach, E.M. CD4+CD25+ immunoregulatory T cells suppress polyclonal T cell activation in vitro by inhibiting interleukin 2 production. J. Exp. Med. 188, 287-296 (1998).

75. Korn, T. et al. Myelin-specific regulatory T cells accumulate in the CNS but fail to control autoimmune inflammation. Nat. Med. 13, 423-431 (2007).

76. Bonertz, A. et al. Antigen-specific Tregs control T cell responses against a limited repertoire of tumor antigens in patients with colorectal carcinoma. J. Clin. Invest. 119, 3311-3321 (2009).

77. Pillemer, B.B. et al. STAT6 activation confers upon Thelper cells resistance to suppression by regulatory T cells. J. Immunol. 183, 155163 (2009).

78. Bettelli, E. et al. Reciprocal developmental pathways for the generation of pathogenic effector TH17 and regulatory T cells. Nature 441, 235-238 (2006).

79. Mangan, P.R. et al. Transforming growth factor-beta induces development of the $T(H) 17$ lineage. Nature 441, 231-234 (2006).

80. Veldhoen, M., Hocking, R.J., Atkins, C.J., Locksley, R.M. \& Stockinger, B. TGFbeta in the context of an inflammatory cytokine milieu supports de novo differentiation of IL-17-producing T cells. Immunity 24, 179-189 (2006).

81. Acosta-Rodriguez, E.V., Napolitani, G., Lanzavecchia, A. \& Sallusto, F. Interleukins 1 beta and 6 but not transforming growth factor-beta are essential for the differentiation of interleukin 17-producing human $T$ helper cells. Nat. Immunol. 8, 942-949 (2007).

82. Rose-John, S. \& Neurath, M.F. IL-6 trans-signaling: the heat is on. Immunity 20, 2-4 (2004).

83. Doganci, A. et al. The IL-6R alpha chain controls lung CD4+CD25+ Treg development and function during allergic airway inflammation in vivo. J. Clin. Invest. 115, 313-325 (2005).

84. Dominitzki, S. et al. Cutting edge: trans-signaling via the soluble IL-6R abrogates the induction of FoxP3 in naive CD4+CD25 T cells. J. Immunol. 179, 2041-2045 (2007).

85. Yang, X.O. et al. STAT3 regulates cytokine-mediated generation of inflammatory helper T cells. J. Biol. Chem. 282, 9358-9363 (2007).

86. Zhang, D.H., Cohn, L., Ray, P., Bottomly, K. \& Ray, A. Transcription factor GATA-3 is differentially expressed in murine Th1 and Th2 cells and controls Th2-specific expression of the interleukin-5 gene. J. Biol. Chem. 272, 21597-21603 (1997).

87. Zheng, W. \& Flavell, R.A. The transcription factor GATA-3 is necessary and sufficient for Th2 cytokine gene expression in CD4 T cells. Cell 89, 587-596 (1997).

88. Takaki, H. et al. STAT6 inhibits TGF-beta1-mediated Foxp3 induction through direct binding to the Foxp3 promoter, which is reverted by retinoic acid receptor. J. Biol. Chem. 283, 14955-14962 (2008).

89. Mantel, P.Y. et al. GATA3-driven Th2 responses inhibit TGF-beta1induced FOXP3 expression and the formation of regulatory T cells. PLOS Biol. 5, e329 (2007).

90. Saito, K. et al. Differential regulatory function of resting and preactivated allergen-specific CD4+ CD25+ regulatory T cells in Th2-type airway inflammation. J. Immunol. 181, 6889-6897 (2008).

91. Pace, L., Rizzo, S., Palombi, C., Brombacher, F. \& Doria, G. Cutting edge: IL-4-induced protection of CD4+CD25 - Th cells from CD4+CD25+ regulatory T cell-mediated suppression. J. Immunol. 176, 3900-3904 (2006).

92. Miyara, M. et al. The immune paradox of sarcoidosis and regulatory $T$ cells. J. Exp. Med. 203, 359-370 (2006).

93. Zhou, X. et al. Instability of the transcription factor Foxp3 leads to the generation of pathogenic memory T cells in vivo. Nat. Immunol. 10, 1000-1007 (2009).

94. Oldenhove, G. et al. Decrease of Foxp3+ Treg cell number and acquisition of effector cell phenotype during lethal infection. Immunity 31, 772-786 (2009).
95. Chaudhry, A. et al. CD4+ regulatory T cells control TH17 responses in a Stat3-dependent manner. Science 326, 986-991 (2009).

96. Koch, M.A. et al. The transcription factor T-bet controls regulatory T cell homeostasis and function during type 1 inflammation. Nat. Immunol. 10, 595-602 (2009).

97. Zheng, Y. et al. Regulatory T-cell suppressor program co-opts transcription factor IRF4 to control T(H)2 responses. Nature 458, 351356 (2009).

98. Zhou, L. et al. IL-6 programs $\mathrm{T}(\mathrm{H})-17$ cell differentiation by promoting sequential engagement of the IL-21 and IL-23 pathways. Nat. Immunol. 8, 967-974 (2007).

99. Zhou, L. et al. TGF-beta-induced Foxp3 inhibits $T(H) 17$ cell differentiation by antagonizing RORgammat function. Nature 453, 236-240 (2008).

100. Yang, X.O. et al. Molecular antagonism and plasticity of regulatory and inflammatory T cell programs. Immunity 29, 44-56 (2008).

101. Sallusto, F., Lenig, D., Mackay, C.R. \& Lanzavecchia, A. Flexible programs of chemokine receptor expression on human polarized $\mathrm{T}$ helper 1 and 2 lymphocytes. J. Exp. Med. 187, 875-883 (1998).

102. Sasai, Y., Kageyama, R., Tagawa, Y., Shigemoto, R. \& Nakanishi, S. Two mammalian helix-loop-helix factors structurally related to Drosophila hairy and enhancer of split. Genes Dev. 6, 2620-2634 (1992).

103. Kageyama, R., Ohtsuka, T. \& Tomita, K. The bHLH gene Hes 1 regulates differentiation of multiple cell types. Mol. Cells 10, 1-7 (2000).

104. Eagar, T.N. et al. Notch 1 signaling regulates peripheral T cell activation. Immunity 20, 407-415 (2004).

105. Nakamura, K., Kitani, A. \& Strober, W. Cell contact-dependent immunosuppression by CD4+CD25+ regulatory T cells is mediated by cell surface-bound transforming growth factor $\beta$. J. Exp. Med. 194, 629644 (2001).

106. Samon, J.B. et al. Notch1 and TGFbeta1 cooperatively regulate Foxp3 expression and the maintenance of peripheral regulatory T cells. Blood 112, 1813-1821 (2008).

107. Amsen, D., Antov, A. \& Flavell, R.A. The different faces of Notch in Thelper-cell differentiation. Nat. Rev. Immunol. 9, 116-124 (2009).

108. Becker, J.C., Czerny, C. \& Brocker, E.B. Maintenance of clonal anergy by endogenously produced IL-10. Int. Immunol. 6, 1605-1612 (1994).

109. Enk, A.H., Saloga, J., Becker, D., Mohamadzadeh, M. \& Knop, J. Induction of hapten-specific tolerance by interleukin 10 in vivo. J. Exp. Med. 179, 1397-1402 (1994).

110. Akdis, C.A. et al. Epitope-specific T cell tolerance to phospholipase A2 in bee venom immunotherapy and recovery by IL-2 and IL-15 in vitro. J. Clin. Invest. 98, 1676-1683 (1996).

111. Gri, G. et al. CD4+CD25+ regulatory T cells suppress mast cell degranulation and allergic responses through OX40-OX40L interaction. Immunity 29, 771-781 (2008).

112. Munn, D.H. \& Mellor, A.L. Indoleamine 2,3-dioxygenase and tumorinduced tolerance. J. Clin. Invest. 117, 1147-1154 (2007).

113. Odemuyiwa, S.O. et al. Cutting edge: human eosinophils regulate T cell subset selection through indoleamine 2,3-dioxygenase. J. Immunol. 173, 5909-5913 (2004).

114. Xu, H. et al. Indoleamine 2,3-dioxygenase in lung dendritic cells promotes Th2 responses and allergic inflammation but is not required for tolerance. Proc. Natl. Acad. Sci. USA 105, 6690-6695 (2008).

115. Montagnoli, C. et al. Immunity and tolerance to Aspergillus involve functionally distinct regulatory T cells and tryptophan catabolism. J. Immunol. 176, 1712-1723 (2006).

116. Wing, K. et al. CTLA-4 control over Foxp3+ regulatory $T$ cell function. Science 322, 271-275 (2008).

117. Collison, L.W. et al. The inhibitory cytokine IL-35 contributes to regulatory T-cell function. Nature 450, 566-569 (2007).

118. Wilson, M.S. et al. Suppression of murine allergic airway disease by IL-2: anti-IL-2 monoclonal antibody-induced regulatory T cells. J. Immunol. 181, 6942-6954 (2008).

119. Liston, A., Lu, L.F., O'Carroll, D., Tarakhovsky, A. \& Rudensky, A.Y. Dicerdependent microRNA pathway safeguards regulatory T cell function. J. Exp. Med. 205, 1993-2004 (2008).

120. Zhou, X. et al. Selective miRNA disruption in T reg cells leads to uncontrolled autoimmunity. J. Exp. Med. 205, 1983-1991 (2008).

121. Kohlhaas, S. et al. Cutting edge: the Foxp3 target miR-155 contributes to the development of regulatory T cells. J. Immunol. 182, 2578-2582 (2009).

122. Lu, L.F. et al. Foxp3-dependent microRNA155 confers competitive fitness to regulatory T cells by targeting SOCS1 protein. Immunity $\mathbf{3 0}$, 80-91 (2009). 
123. Rodriguez, A. et al. Requirement of bic/microRNA-155 for normal immune function. Science 316, 608-611 (2007).

124. Thai, T.H. et al. Regulation of the germinal center response by microRNA-155. Science 316, 604-608 (2007).

125. Baecher-Allan, C., Brown, J.A., Freeman, G.J. \& Hafler, D.A. $\mathrm{CD} 4+\mathrm{CD} 25$ high regulatory cells in human peripheral blood. J. Immunol. 167, 1245-1253 (2001).

126. Fisson, S. et al. Therapeutic potential of self-antigen-specific CD4+ CD25+ regulatory $T$ cells selected in vitro from a polyclonal repertoire. Eur. J. Immunol. 36, 817-827 (2006).

127. Masteller, E.L., Tang, Q. \& Bluestone, J.A. Antigen-specific regulatory T cells-ex vivo expansion and therapeutic potential. Semin. Immunol. 18, 103-110 (2006).

128. Tran, D.Q., Ramsey, H. \& Shevach, E.M. Induction of FOXP3 expression in naive human CD4+FOXP3 T cells by T-cell receptor stimulation is transforming growth factor-beta dependent but does not confer a regulatory phenotype. Blood 110, 2983-2990 (2007).

129. Selvaraj, R.K. \& Geiger, T.L. A kinetic and dynamic analysis of Foxp3 induced in T cells by TGF-beta. J. Immunol 179, 1390 (2007).

130. Floess, S. et al. Epigenetic control of the foxp3 locus in regulatory T cells. PLoS Biol. 5, e38 (2007).

131. Wan, Y.Y. \& Flavell, R.A. Regulatory T-cell functions are subverted and converted owing to attenuated Foxp3 expression. Nature 445, 766-770 (2007).

132. Mucida, D. et al. Retinoic acid can directly promote TGF-beta-mediated Foxp3(+) Treg cell conversion of naive T cells. Immunity 30, 471-472; author reply 472-473 (2009).

133. Wang, J., Huizinga, T.W. \& Toes, R.E. De novo generation and enhanced suppression of human $\mathrm{CD} 4+\mathrm{CD} 25+$ regulatory T cells by retinoic acid. $J$. Immunol. 183, 4119-4126 (2009).

134. Xiao, S. et al. Retinoic acid increases Foxp3+ regulatory T cells and inhibits development of Th17 cells by enhancing TGF-beta-driven Smad3 signaling and inhibiting IL-6 and IL-23 receptor expression. J. Immunol. 181, 2277-2284 (2008).

135. Hill, J.A. et al. Retinoic acid enhances Foxp3 induction indirectly by relieving inhibition from CD4+CD44hi cells. Immunity $\mathbf{2 9}$, 758-770 (2008).

136. Elias, K.M. et al. Retinoic acid inhibits Th17 polarization and enhances FoxP3 expression through a Stat-3/Stat-5 independent signaling pathway. Blood 111, 1013-1020 (2008).

137. Moore, C. et al. Transforming growth factor-beta and all-trans retinoic acid generate ex vivo transgenic regulatory $T$ cells with intestinal homing receptors. Transplant Proc. 41, 2670-2672 (2009).

138. Benson, M.J., Pino-Lagos, K., Rosemblatt, M. \& Noelle, R.J. All-trans retinoic acid mediates enhanced $T$ reg cell growth, differentiation, and gut homing in the face of high levels of co-stimulation. J. Exp. Med. 204, 1765-1774 (2007).

139. Mucida, D. et al. Reciprocal TH17 and regulatory T cell differentiation mediated by retinoic acid. Science 317, 256-260 (2007).

140. Ross, A.C. On the sources of retinoic acid in the lung: understanding the local conversion of retinol to retinoic acid. Am. J. Physiol. Lung Cell Mol. Physiol. 286, L247-L248 (2004).

141. Mucida, D., Park, Y. \& Cheroutre, H. From the diet to the nucleus: vitamin $A$ and TGF-beta join efforts at the mucosal interface of the intestine. Semin. Immunol. 21, 14-21 (2009).

142. Jetten, A.M. Retinoid-related orphan receptors (RORs): critical roles in development, immunity, circadian rhythm, and cellular metabolism. Nucl. Recept. Signal 7, e003 (2009).

143. Dirami, G. et al. Lung retinol storing cells synthesize and secrete retinoic acid, an inducer of alveolus formation. Am. J. Physiol. Lung Cell Mol. Physiol. 286, L249-L256 (2004).

144. Goswami, S. et al. Divergent functions for airway epithelial matrix metalloproteinase 7 and retinoic acid in experimental asthma. Nat. Immunol. 10, 496-503 (2009).

145. Maret, M. et al. Liposomal retinoic acids modulate asthma manifestations in mice. J. Nutr. 137, 2730-2736 (2007).

146. Dawson, H. et al. Localized Th1-, Th2-, T regulatory cell-, and inflammation-associated hepatic and pulmonary immune responses in Ascaris suum-infected swine are increased by retinoic acid. Infect. Immun. 77, 2576-2587 (2009).

147. el Mansouri, S. et al. Time- and dose-dependent kinetics of all-transretinoic acid in rats after oral or intravenous administration(s). Drug Metab. Dispos. 23, 227-231 (1995).
148. Ueki, S. et al. Retinoic acids are potent inhibitors of spontaneous human eosinophil apoptosis. J. Immunol. 181, 7689-7698 (2008).

149. Dawson, H.D. et al. Direct and indirect effects of retinoic acid on human Th2 cytokine and chemokine expression by human T lymphocytes. BMC Immunol. 7, 27 (2006).

150. Iwata, M., Eshima, Y. \& Kagechika, H. Retinoic acids exert direct effects on T cells to suppress Th1 development and enhance Th2 development via retinoic acid receptors. Int. Immunol. 15, 1017-1025 (2003).

151. Hypponen, E. et al. Infant vitamin d supplementation and allergic conditions in adulthood: northern Finland birth cohort 1966. Ann. NY Acad. Sci. 1037, 84-95 (2004).

152. Wjst, M. \& Dold, S. Genes, factor $X$, and allergens: what causes allergic diseases? Allergy 54, 757-759 (1999).

153. Matheu, V., Back, O., Mondoc, E. \& Issazadeh-Navikas, S. Dual effects of vitamin D-induced alteration of $\mathrm{TH} 1 / \mathrm{TH} 2$ cytokine expression: enhancing lgE production and decreasing airway eosinophilia in murine allergic airway disease. J. Allergy Clin. Immunol. 112, 585-592 (2003).

154. Topilski, I. et al. The anti-inflammatory effects of 1,25-dihydroxyvitamin D3 on Th2 cells in vivo are due in part to the control of integrin-mediated T lymphocyte homing. Eur. J. Immunol. 34, 1068-1076 (2004).

155. Sigmundsdottir, H. \& Butcher, E.C. Environmental cues, dendritic cells and the programming of tissue-selective lymphocyte trafficking. Nat. Immunol. 9, 981-987 (2008).

156. Wjst, M. The vitamin D slant on allergy. Pediatr. Allergy Immunol. 17, 477-483 (2006).

157. Szatmari, I. \& Nagy, L. Nuclear receptor signalling in dendritic cells connects lipids, the genome and immune function. EMBO J. 27, 23532362 (2008).

158. Barrat, F.J. et al. In vitro generation of interleukin 10-producing regulatory CD4(+) T cells is induced by immunosuppressive drugs and inhibited by Thelper type 1 (Th1)- and Th2-inducing cytokines. J. Exp. Med. 195, 603-616 (2002).

159. O'Garra, A. \& Barrat, F.J. In vitro generation of IL-10-producing regulatory $\mathrm{CD} 4+\mathrm{T}$ cells is induced by immunosuppressive drugs and inhibited by Th1- and Th2-inducing cytokines. Immunol. Lett. 85, 135139 (2003).

160. Gorman, S. et al. Topically applied 1,25-dihydroxyvitamin D3 enhances the suppressive activity of CD4+CD25+ cells in the draining lymph nodes. J. Immunol. 179, 6273-6283 (2007).

161. Cantorna, M.T., Hayes, C.E. \& DeLuca, H.F. 1,25Dihydroxycholecalciferol inhibits the progression of arthritis in murine models of human arthritis. J. Nutr. 128, 68-72 (1998).

162. Cantorna, M.T., Woodward, W.D., Hayes, C.E. \& DeLuca, H.F. 1,25dihydroxyvitamin D3 is a positive regulator for the two antiencephalitogenic cytokines TGF-beta 1 and IL-4. J. Immunol. 160, 5314-5319 (1998).

163. Staeva-Vieira, T.P. \& Freedman, L.P. 1,25-dihydroxyvitamin D3 inhibits IFN-gamma and IL-4 levels during in vitro polarization of primary murine CD4+ T cells. J. Immunol. 168, 1181-1189 (2002).

164. O'Kelly, J. et al. Normal myelopoiesis but abnormal T lymphocyte responses in vitamin D receptor knockout mice. J. Clin. Invest. 109, 1091-1099 (2002).

165. Wittke, A. et al. Vitamin D receptor expression by the lung microenvironment is required for maximal induction of lung inflammation. Arch. Biochem. Biophys. 460, 306-313 (2007).

166. Taher, Y.A., van Esch, B.C., Hofman, G.A., Henricks, P.A. \& van Oosterhout, A.J. 1alpha,25-dihydroxyvitamin D3 potentiates the beneficial effects of allergen immunotherapy in a mouse model of allergic asthma: role for IL-10 and TGF-beta. J. Immunol. 180, 5211-5221 (2008).

167. Wittke, A., Weaver, V., Mahon, B.D., August, A. \& Cantorna, M.T. Vitamin $D$ receptor-deficient mice fail to develop experimental allergic asthma. J. Immunol. 173, 3432-3436 (2004).

168. Noon, L. Prophylactic inoculation of hay fever. Lancet 1, 1572-1573 (1911).

169. Noon, L. Prophylactic inoculation against hay fever (historical document). Ann. Allergy 13, 713-716; passim (1955).

170. Francis, J.N., Till, S.J. \& Durham, S.R. Induction of IL-10+CD4+CD25+ T cells by grass pollen immunotherapy. J. Allergy Clin. Immunol. 111, 1255-1261 (2003).

171. Akdis, C.A., Blesken, T., Akdis, M., Wuthrich, B. \& Blaser, K. Role of interleukin 10 in specific immunotherapy. J. Clin. Invest 102, 98-106 (1998). 
172. Jutel, M. et al. IL-10 and TGF-beta cooperate in the regulatory T cell response to mucosal allergens in normal immunity and specific immunotherapy. Eur. J. Immunol. 33, 1205-1214 (2003).

173. O'Hehir, R.E. et al. House dust mite sublingual immunotherapy: the role for transforming growth factor-beta and functional regulatory T cells. Am. J. Respir. Crit. Care Med. 180, 936-947 (2009).

174. Akdis, C.A. \& Akdis, M. Mechanisms and treatment of allergic disease in the big picture of regulatory T cells. J. Allergy Clin. Immunol. 123, 735746; quiz 747-738 (2009).

175. Wilson, D.R., Torres, L.I. \& Durham, S.R. Sublingual immunotherapy for allergic rhinitis. Cochrane Database Syst. Rev. CD002893 (2003).

176. Muller, U. et al. Successful immunotherapy with T-cell epitope peptides of bee venom phospholipase A2 induces specific T-cell anergy in patients allergic to bee venom. J. Allergy Clin. Immunol. 101, 747-754 (1998).

177. Pereira-Santos, M.C. et al. Expansion of circulating Foxp3+)D25bright CD4+ T cells during specific venom immunotherapy. Clin. Exp. Allergy 38, 291-297 (2008).

178. Abramson, M.J., Puy, R.M. \& Weiner, J.M. Is allergen immunotherapy effective in asthma? A meta-analysis of randomized controlled trials. Am. J. Respir. Crit. Care Med. 151, 969-974 (1995).

179. Bousquet, J. \& Michel, F.B. Specific immunotherapy in asthma: is it effective? J. Allergy Clin. Immunol. 94, 1-11 (1994).

180. Bousquet, J., Michel, F.B. \& Malling, H.J. Is allergen immunotherapy effective in asthma? A meta-analysis of randomized clinical trials. Am. J. Respir. Crit. Care Med. 152, 1737-1738 (1995).

181. Abramson, M.J., Puy, R.M. \& Weiner, J.M. Allergen immunotherapy for asthma. Cochrane Database Syst. Rev. CD001186 (2003).

182. Moller, C. et al. Pollen immunotherapy reduces the development of asthma in children with seasonal rhinoconjunctivitis (the PAT-study). J. Allergy Clin. Immunol. 109, 251-256 (2002).

183. Jacobsen, L. et al. Specific immunotherapy has long-term preventive effect of seasonal and perennial asthma: 10-year follow-up on the PAT study. Allergy 62, 943-948 (2007).

184. Rolland, J.M., Gardner, L.M. \& O'Hehir, R.E. Allergen-related approaches to immunotherapy. Pharmacol. Ther. 121, 273-284 (2009).

185. Bousquet, J., Michel, F.B. \& Vignola, A.M. Allergen immunotherapy: therapeutic vaccines for asthma. Clin. Allergy Immunol. 18, 511-528 (2004).

186. Larche, M., Akdis, C.A. \& Valenta, R. Immunological mechanisms of allergen-specific immunotherapy. Nat. Rev. Immunol. 6, 761-771 (2006).

187. Akdis, M. \& Akdis, C.A. Mechanisms of allergen-specific immunotherapy. J. Allergy Clin. Immunol. 119, 780-791 (2007).

188. Broide, D.H. Immunomodulation of allergic disease. Annu. Rev. Med. 60, 279-291 (2009).

189. Larche, M. \& Wraith, D.C. Peptide-based therapeutic vaccines for allergic and autoimmune diseases. Nat. Med. 11, S69-S76 (2005).

190. Larche, M. Immunotherapy with peptides. Eur. Ann. Allergy Clin. Immunol. 38, 240-243 (2006).

191. Larche, M. Peptide immunotherapy for allergic diseases. Allergy 62 , 325-331 (2007).

192. Oldfield, W.L., Kay, A.B. \& Larche, M. Allergen-derived T cell peptideinduced late asthmatic reactions precede the induction of antigenspecific hyporesponsiveness in atopic allergic asthmatic subjects. J. Immunol. 167, 1734-1739 (2001).

193. Oldfield, W.L., Larche, M. \& Kay, A.B. Effect of T-cell peptides derived from Fel $\mathrm{d} 1$ on allergic reactions and cytokine production in patients sensitive to cats: a randomised controlled trial. Lancet 360, 47-53 (2002).

194. Van Overtvelt, L. et al. IL-10-inducing adjuvants enhance sublingual immunotherapy efficacy in a murine asthma model. Int. Arch. Allergy Immunol. 145, 152-162 (2008).

195. Verhoef, A., Alexander, C., Kay, A.B. \& Larche, M. T cell epitope immunotherapy induces a CD4+ T cell population with regulatory activity. PLoS Med. 2, e78 (2005).

196. Alexander, C., Ying, S., A, B.K. \& Larche, M. Fel d 1-derived T cell peptide therapy induces recruitment of CD4+CD25+; CD4+ interferon-gamma+ Thelper type 1 cells to sites of allergen-induced late-phase skin reactions in cat-allergic subjects. Clin. Exp. Allergy 35, 52-58 (2005).

197. Fellrath, J.M. et al. Allergen-specific T-cell tolerance induction with allergen-derived long synthetic peptides: results of a phase I trial. J. Allergy Clin. Immunol. 111, 854-861 (2003).

198. Tarzi, M. et al. Induction of interleukin-10 and suppressor of cytokine signalling-3 gene expression following peptide immunotherapy. Clin. Exp. Allergy 36, 465-474 (2006).
199. Karagiannidis, C. et al. Glucocorticoids upregulate FOXP3 expression and regulatory T cells in asthma. J. Allergy Clin. Immunol. 114, 1425-1433 (2004).

200. John, M. et al. Inhaled corticosteroids increase interleukin-10 but reduce macrophage inflammatory protein-1alpha, granulocyte-macrophage colonystimulating factor, and interferon-gamma release from alveolar macrophages in asthma. Am. J. Respir. Crit. Care Med. 157, 256-262 (1998).

201. Stelmach, I., Jerzynska, J. \& Kuna, P. A randomized, double-blind trial of the effect of glucocorticoid, antileukotriene and beta-agonist treatment on IL-10 serum levels in children with asthma. Clin. Exp. Allergy 32, 264-269 (2002).

202. Hartl, D. et al. Quantitative and functional impairment of pulmonary CD4+CD25hi regulatory T cells in pediatric asthma. J. Allergy Clin. Immunol. 119, 1258-1266 (2007).

203. Stock, P., Akbari, O., DeKruyff, R.H. \& Umetsu, D.T. Respiratory tolerance is inhibited by the administration of corticosteroids. J. Immunol. 175, 7380-7387 (2005).

204. Kopf, H., de la Rosa, G.M., Howard, O.M. \& Chen, X. Rapamycin inhibits differentiation of Th17 cells and promotes generation of FoxP3+ T regulatory cells. Int. Immunopharmacol. 7, 1819-1824 (2007).

205. Coenen, J.J. et al. Rapamycin, not cyclosporine, permits thymic generation and peripheral preservation of CD4+ CD25+ FoxP3+ T cells. Bone Marrow Transplant. 39, 537-545 (2007).

206. Battaglia, M. et al. Rapamycin and interleukin-10 treatment induces $T$ regulatory type 1 cells that mediate antigen-specific transplantation tolerance. Diabetes 55, 40-49 (2006).

207. Battaglia, M. et al. Rapamycin promotes expansion of functional CD4+CD25+FOXP3+ regulatory $T$ cells of both healthy subjects and type 1 diabetic patients. J. Immunol. 177, 8338-8347 (2006).

208. Keever-Taylor, C.A. et al. Rapamycin enriches for CD4(+) CD25(+) CD27(+) Foxp3(+) regulatory T cells in ex vivo-expanded CD25-enriched products from healthy donors and patients with multiple sclerosis. Cytotherapy 9, 144-157 (2007).

209. Strauss, L. et al. Selective survival of naturally occurring human CD4+CD25+Foxp3+ regulatory T cells cultured with rapamycin. J. Immunol. 178, 320-329 (2007).

210. Miyara, M., Wing, K. \& Sakaguchi, S. Therapeutic approaches to allergy and autoimmunity based on FoxP3+ regulatory T-cell activation and expansion. J. Allergy Clin. Immunol. 123, 749-755; quiz 756-747 (2009).

211. Long, S.A. \& Buckner, J.H. Combination of rapamycin and IL-2 increases de novo induction of human CD4(+)CD25(+)FOXP3(+) T cells. J. Autoimmun. 30, 293-302 (2008).

212. Coenen, J.J., Koenen, H.J., van Rijssen, E., Hilbrands, L.B. \& Joosten, I. Rapamycin, and not cyclosporin A, preserves the highly suppressive CD27+ subset of human CD4+CD25+ regulatory T cells. Blood 107, 1018-1023 (2006).

213. Bocian, K. et al. Rapamycin, unlike cyclosporine A, enhances suppressive functions of in vitro-induced CD4+CD25+ Tregs. Nephrol. Dial. Transplant. (2009).

214. Basu, S., Golovina, T., Mikheeva, T., June, C.H. \& Riley, J.L. Cutting edge: Foxp3-mediated induction of pim 2 allows human T regulatory cells to preferentially expand in rapamycin. J. Immunol. 180, 5794-5798 (2008).

215. Qu, Y. et al. The effect of immunosuppressive drug rapamycin on regulatory CD4+CD25+Foxp3+T cells in mice. Transpl. Immunol. 17, 153-161 (2007).

216. Eynott, P.R. et al. Effects of cyclosporin $A$ and a rapamycin derivative (SAR943) on chronic allergic inflammation in sensitized rats. Immunology 109, 461-467 (2003).

217. Corrigan, C.J. Asthma refractory to glucocorticoids: the role of newer immunosuppressants. Am. J. Respir. Med. 1, 47-54 (2002).

218. Fujitani, Y. \& Trifilieff, A. In vivo and in vitro effects of SAR 943, a rapamycin analogue, on airway inflammation and remodeling. Am. J. Respir. Crit. Care Med. 167, 193-198 (2003).

219. Krymskaya, V.P. Targeting the phosphatidylinositol 3-kinase pathway in airway smooth muscle: rationale and promise. BioDrugs 21, 85-95 (2007).

220. Pace, L., Pioli, C. \& Doria, G. IL-4 modulation of CD4+CD25+ Tregulatory cell-mediated suppression. J. Immunol. 174, 7645-7653 (2005).

221. Hori, S., Nomura, T. \& Sakaguchi, S. Control of regulatory T cell development by the transcription factor Foxp3. Science 299, 1057-1061 (2003).

222. Kleinewietfeld, M. et al. CD49d provides access to "untouched" human Foxp3+ Treg free of contaminating effector cells. Blood 113, 827-836 (2009).

223. Chen, Y., Kuchroo, V.K., Inobe, J., Hafler, D.A. \& Weiner, H.L. Regulatory $T$ cell clones induced by oral tolerance: suppression of autoimmune encephalomyelitis. Science 265, 1237-1240 (1994). 